\title{
Finite lattice distortion patterns in plastically deformed zircon grains
}

\author{
E. Kovaleva ${ }^{1}$, U. Klötzli ${ }^{1}$, G. Habler ${ }^{1}$, and E. Libowitzky ${ }^{2}$ \\ ${ }^{1}$ Department of Lithospheric Research, Faculty of Earth Sciences, Geography and Astronomy, University of Vienna, \\ Althanstrasse 14, 1090 Vienna, Austria \\ ${ }^{2}$ Department of Mineralogy and Crystallography, Faculty of Earth Sciences, Geography and Astronomy, \\ University of Vienna, Althanstrasse 14, 1090 Vienna, Austria \\ Correspondence to: E. Kovaleva (elizaveta.kovaleva@univie.ac.at)
}

Received: 27 June 2014 - Published in Solid Earth Discuss.: 25 July 2014

Revised: 30 September 2014 - Accepted: 5 October 2014 - Published: 18 November 2014

\begin{abstract}
This study examines finite deformation patterns of zircon grains from high-temperature natural shear zones. Various zircon-bearing rocks were collected in the Western Tauern Window, eastern Alps, where they were deformed under amphibolite facies conditions, and in the Ivrea-Verbano Zone (IVZ), southern Alps, where deformation is related with granulite-facies metamorphism. Among the sampled rocks are granitic orthogneisses, metalamprophyres and paragneisses, all of which are strongly deformed.

The investigated zircon grains ranging from 10 to $50 \mu \mathrm{m}$ were studied in situ using a combination of scanning electron microscope (SEM) techniques, backscattered electron (BSE) imaging, forward-scattered electron (FSE) imaging, cathodoluminescence (CL) imaging, and crystallographic orientation mapping by electron backscatter diffraction (EBSD), as well as micro-Raman spectroscopy. Energy-dispersive X-ray spectrometry (EDS) was applied to host phases.

Microstructural analysis of crystal-plastically deformed zircon grains was based on high-resolution EBSD maps. Three general types of finite lattice distortion patterns were detected: type (I) is defined by gradual bending of the zircon lattice with orientation changes of about $0.6-1.8^{\circ}$ per micrometer without subgrain boundary formation. Cumulative grain-internal orientation variations range from 7 to $25^{\circ}$ within single grains. Type (II) represents local gradual bending of the crystal lattice accompanied by the formation of subgrain boundaries that have concentric semicircular shapes in 2-D sections. Cumulative grain-internal orientation variations range from 15 to $40^{\circ}$ within single grains. Type (III) is characterized by formation of subgrains separated by a well-
\end{abstract}

defined subgrain boundary network, where subgrain boundaries show a characteristic angular closed contour. The cumulative orientation variation within a single grain ranges from 3 to $10^{\circ}$. Types (I) and (II) predominate in granulite facies rocks, whereas type (III) is restricted to the amphibolite facies rocks. The difference in distortion patterns is controlled by strain rate and by ratio between dislocation formation and dislocation motion rates, conditioned by the amount of differential stress.

Investigated microstructures demonstrate that misorientation axes are usually parallel to the $<001>$ and $<100>$ crystallographic directions; dominant slips are $<010>\{001\}, \quad<010>\{100\}$ and $<001>\{010\}$, whereas in some grains cross-slip takes place. This study demonstrates that activation of energetically preferable slip systems is facilitated if zircon grain is decoupled from the host matrix and/or hosted by a soft phase.

\section{Introduction}

\subsection{Zircon and its significance in geosciences}

Zircon is one of the most stable and abundant accessory phases in many rock types. Due to its chemical stability and ability to incorporate and preserve radioactive uranium and rare earth elements (REE) zircon is widely used for isotopic mineral dating (e.g., Davis et al., 2003; Klötzli et al., 2014), for the geochemical characterization of its forming environment (e.g., Hofmann et al., 2009; Nemchin et 
al., 2009; Erdmann et al., 2013), and for the estimations of (re)crystallization temperature (Watson et al., 2006). Volume diffusion of $\mathrm{Pb}$ and $\mathrm{Ti}$ cations in a pristine zircon crystal is usually insignificant throughout the geological history, which allows us to estimate the timing and temperature of mineral formation. For example, at $850^{\circ} \mathrm{C}$, a volume diffusion length of $5 \mu \mathrm{m}$ would require about 10 million years for $\mathrm{Pb}, 1 \mathrm{bil}-$ lion years for Dy, and tens of billions of years for Ti (Cherniak and Watson, 2003). However, at lower temperatures, other mechanisms of enhanced diffusion have been documented in natural samples, especially so-called "Pb loss", which is not consistent with experimental predictions for volume diffusion (e.g., Geisler et al., 2002). In the past, the common explanation for low-temperature diffusion in zircon was the effect of self-irradiation that causes metamictization and thus induces/enhances volume diffusion (Cherniak et al., 1991; Cherniak and Watson, 2003). Recently, a number of authors found evidence for increased trace element diffusion in zircon due to crystal-plastic deformation (Erickson et al., 2013a, b; Flowers et al., 2010; Grange et al., 2013; Kaczmarek et al., 2011; MacDonald el al., 2013; Moser et al., 2009, 2011; Nemchin et al., 2009; Piazolo et al., 2012; Reddy et al., 2006, 2007, 2009; Reddy and Timms, 2010; Schwartz et al., 2010; Timms and Reddy, 2009; Timms et al., 2006, 2011, 2012a, b). These authors have shown that crystalplastic deformation can dramatically affect the content of trace elements in zircon domains and can therefore cause isotopic system resetting. Deformation microstructures such as subgrain boundaries, formed by dislocation creep and recovery, may act as fluid migration and fast element-diffusion pathways that cause local variations in the chemical and isotopic compositions of grains (Timms et al., 2006, 2011). So far there have only been a few documentations of these phenomena presented in the literature mentioned above, but it has already been clearly demonstrated that crystal-plastic deformation of zircon affects the interpretation of radiometric age data (e.g., Reddy et al., 2007; Timms et al., 2011, 2012a; Grange et al., 2013). Therefore it is crucial to decipher the controlling mechanisms and general features of zircon lattice distortion that may cause enhanced material transport through the crystal. The current study aims to classify and characterize different finite crystal-plastic deformation patterns of zircon found in natural rocks by comparing samples from different metamorphic environments and from various associations of host phases.

\subsection{Targeted material}

Many of the previous detailed microstructural analyses on crystal-plastic deformation of zircon crystals have focused on comparatively large zircons, from $200 \mu \mathrm{m}$ up to a few millimeters in length. Some of those zircons were derived from uncommon occurrences: (1) an impact basin (Moser et al., 2009, 2011); (2) zircon-rich veins veins within a metaanorthositic body (Piazolo et al., 2012); (3) olivine gabbro derived from the ocean ridge (Reddy et al., 2006, 2007; Timms and Reddy, 2009); or (4) xenolith from kimberlitic pipe (Timms et al., 2011). Other studies were focused on more widespread rock types and smaller zircons grains, less than $100 \mu \mathrm{m}$ in length (Flowers et al., 2010; Kaczmarek et al., 2011; MacDonald et al., 2013; Reddy and Timms 2010; Schwarzt et al., 2010; Timms et al., 2012b). In addition, some of the studies examined embedded zircon grains that were extracted from the sample by means of heavy mineral separation (e.g., Kaczmarek et al., 2011; Moser at al., 2011; Reddy et al., 2009; Schwartz et al., 2010; Timms and Reddy, 2009; Timms at al., 2006). During the conventional procedure of extracting larger grains by classical mineral separation techniques, the context of host minerals and the immediate environment is lost, which restricts interpretations and conclusions. Furthermore, deformed grains may be selectively destroyed during sample crushing and sieving. However, in the last years, a growing number of works have appeared that also study crystal-plastically deformed zircons in situ (e.g., Kaczmarek et al., 2011; McDonald et al., 2013; Piazolo et al., 2012; Timms et al., 2011). Following this trend, the current work presents new microstructural data from crystalplastically deformed zircon grains from common lithologies, where zircon grain sizes range from 10 to $50 \mu \mathrm{m}$ in length. As this is a very common grain size of zircon in natural rocks (Silver and Deutsch, 1963; Corfu et al., 2003; MacDonald et al., 2013), the data and resulting systematics are expected to be representative of the majority of zircons from various geological environments. All presented analyses were derived from thin sections of rock samples, allowing microstructural interpretations in host mineral context. The crystallographic orientation of mineral grains or grain domains was analyzed using electron backscatter diffraction (EBSD). This technique provides data at submicrometer-scale spatial resolution and allows in situ examination of grains of few to tens of micrometers in size.

\subsection{Crystal-plastic deformation}

A single crystal exposed to shear stresses deforms elastically at the initial deformation stage, but if the applied shear stresses exceed the elastic limit, geometrically necessary dislocations (GNDs) are generated in the lattice in order to accommodate the strain (Nye, 1953; Wheeler et al., 2008; Dahlberg et al., 2014). Crystal-plastic deformation of individual crystals is assumed to be a consequence of formation and motion of dislocations (lattice line defects) caused by differential stress (Drury and Urai, 1990; Poirier, 1985; Timms et al., 2011). Migration of dislocations by climb is a thermally activated process; migration by glide is a stressinduced process. At tectonic conditions that allow dislocations to move through the crystal lattice, the crystal deforms plastically by slip along a densely packed crystallographic plane. Slip direction $[u v w]$ and slip plane $(h k l)$ are described by Miller indices and define a slip system $[u v w](h k l)$ (Poirier, 
Table 1. List of samples and zircon grains discussed in this study, basic information. WTW: Western Tauern Window; IVZ: Ivrea-Verbano Zone.

\begin{tabular}{|c|c|c|c|c|c|c|c|c|c|}
\hline $\begin{array}{l}\text { Location and } \\
\text { shear zone } \mathrm{N}\end{array}$ & $\begin{array}{l}\text { Metamorphic } \\
\text { grade }\end{array}$ & $\begin{array}{l}\text { Rock type and } \\
\text { degree of } \\
\text { strain }\end{array}$ & $\begin{array}{l}\text { Zircon } \\
\text { grain size } \\
\text { range }\end{array}$ & $\begin{array}{l}\text { Subgrain } \\
\text { size range }\end{array}$ & $\begin{array}{l}\text { Sample and } \\
\text { grain } \mathrm{N}\end{array}$ & $\begin{array}{l}\text { Zircon } \\
\text { length }\end{array}$ & $\begin{array}{l}\text { Host phase(s) } \\
\text { for zircon }\end{array}$ & $\begin{array}{l}\text { Type of } \\
\text { lattice } \\
\text { distortion } \\
\text { zircon }\end{array}$ & $\begin{array}{l}\text { Misorientation } \\
\text { axes }\end{array}$ \\
\hline $\begin{array}{l}\text { WTW, shear } \\
\text { zone } 1\end{array}$ & $\begin{array}{l}\text { Amphibolite } \\
\text { facies }\end{array}$ & $\begin{array}{l}\text { Mylonitic } \\
\text { strongly } \\
\text { foliated } \\
\text { muscovite-biotite } \\
\text { orthogneiss }\end{array}$ & $2-50 \mu \mathrm{m}$ & $4-15 \mu \mathrm{m}$ & $\begin{array}{l}\text { BH12-01-I, } \\
\text { grain } 29\end{array}$ & $40 \mu \mathrm{m}$ & Muscovite & $\begin{array}{l}\text { No } \\
\text { lattice } \\
\text { distortion }\end{array}$ & - \\
\hline $\begin{array}{l}\text { WTW, shear } \\
\text { zone } 1\end{array}$ & $\begin{array}{l}\text { Amphibolite } \\
\text { facies }\end{array}$ & $\begin{array}{l}\text { Ultramylonite, } \\
\text { core of the } \\
\text { shear zone in } \\
\text { granitic } \\
\text { orthogneisses }\end{array}$ & $5-20 \mu \mathrm{m}$ & $2-5 \mu \mathrm{m}$ & $\begin{array}{l}\text { BH12-01-II, } \\
\text { grain 22, }\end{array}$ & $20 \mu \mathrm{m}$ & Plagioclase & $\begin{array}{l}\text { Type } \\
\text { (III) }\end{array}$ & $<103>$ \\
\hline $\begin{array}{l}\text { WTW, shear } \\
\text { zone } 1\end{array}$ & $\begin{array}{l}\text { Amphibolite } \\
\text { facies }\end{array}$ & $\begin{array}{l}\text { Foliated biotite } \\
\text { orthogneiss }\end{array}$ & $2-50 \mu \mathrm{m}$ & $2-15 \mu \mathrm{m}$ & $\begin{array}{l}\text { BH12-02, grain } \\
45\end{array}$ & $50 \mu \mathrm{m}$ & $\begin{array}{l}\text { Plagioclase and } \\
\text { quartz }\end{array}$ & $\begin{array}{l}\text { Cataclastic } \\
\text { deformation }\end{array}$ & $\begin{array}{l}<113>\text { and } \\
<311>\end{array}$ \\
\hline $\begin{array}{l}\text { WTW, shear } \\
\text { zone } 1\end{array}$ & $\begin{array}{l}\text { Amphibolite } \\
\text { facies }\end{array}$ & $\begin{array}{l}\text { Non-foliated } \\
\text { granitic } \\
\text { orthogneisses }\end{array}$ & $2-50 \mu \mathrm{m}$ & $1-7 \mu \mathrm{m}$ & $\begin{array}{l}\text { BH12-04, grain } \\
11\end{array}$ & $\begin{array}{l}22 \mu \mathrm{m} \\
5 \mu \mathrm{m}\end{array}$ & Plagioclase & Type (III) & $<110>-<320$ \\
\hline $\begin{array}{l}\text { WTW, shear } \\
\text { zone } 2\end{array}$ & $\begin{array}{l}\text { Amphibolite } \\
\text { facies }\end{array}$ & $\begin{array}{l}\text { Weakly } \\
\text { foliated granitic } \\
\text { orthogneisses }\end{array}$ & $10-100 \mu \mathrm{m}$ & $7-12 \mu \mathrm{m}$ & $\begin{array}{l}\text { BH12-05, grain } \\
07\end{array}$ & $50 \mu \mathrm{m}$ & Biotite & Type (III) & Cross-slip \\
\hline $\begin{array}{l}\text { WTW, shear } \\
\text { zone } 2\end{array}$ & $\begin{array}{l}\text { Amphibolite } \\
\text { facies }\end{array}$ & $\begin{array}{l}\text { Mafic dyke, } \\
\text { strongly foliated }\end{array}$ & $10-30 \mu \mathrm{m}$ & $1-10 \mu \mathrm{m}$ & $\begin{array}{l}\mathrm{BH} 12-07, \\
\text { grains 03a, 04, } \\
28,31 \mathrm{~b}\end{array}$ & $15-25 \mu \mathrm{m}$ & Biotite, chlorite & Type (III) & $<001>$ \\
\hline $\begin{array}{l}\text { WTW, shear } \\
\text { zone } 2\end{array}$ & $\begin{array}{l}\text { Amphibolite } \\
\text { facies }\end{array}$ & $\begin{array}{l}\text { Mafic dyke, } \\
\text { strongly foliated }\end{array}$ & $10-30 \mu \mathrm{m}$ & $1-10 \mu \mathrm{m}$ & $\begin{array}{l}\text { BH12-07, grain } \\
15 \mathrm{a}\end{array}$ & $15 \mu \mathrm{m}$ & Biotite & Type (III) & $\begin{array}{l}<100>\text { and } \\
<001>\end{array}$ \\
\hline $\begin{array}{l}\text { IVZ, } \\
\text { shear zone } 3\end{array}$ & $\begin{array}{l}\text { Granulite } \\
\text { facies }\end{array}$ & $\begin{array}{l}\text { Stronalite } \\
\text { (non-foliated } \\
\text { metasediment) }\end{array}$ & $20-50 \mu \mathrm{m}$ & $0.5-3 \mu \mathrm{m}$ & $\begin{array}{l}\text { IV12-06C, } \\
\text { grain } 05\end{array}$ & $22 \mu \mathrm{m}$ & $\begin{array}{l}\text { Garnet and } \\
\text { plagioclase }\end{array}$ & Type (II) & $\begin{array}{l}<100>\text { and } \\
<331>\end{array}$ \\
\hline $\begin{array}{l}\text { IVZ, } \\
\text { shear zone } 3\end{array}$ & $\begin{array}{l}\text { Granulite } \\
\text { facies }\end{array}$ & $\begin{array}{l}\text { Stronalite } \\
\text { (non-foliated } \\
\text { metasediment) }\end{array}$ & $20-50 \mu \mathrm{m}$ & - & $\begin{array}{l}\text { IV12-06C, } \\
\text { grain } 16\end{array}$ & $53 \mu \mathrm{m}$ & Plagioclase & Type (I) & $<001>$ \\
\hline
\end{tabular}

1985). During recovery dislocations migrate and accumulate within so-called "dislocation walls", "subgrain boundaries" or "low-angle boundaries" (e.g., Jenkins and Mellor, 1935; McLean, 1952; Sellars, 1978; Urai et al., 1986). Arrays of edge dislocations with the same Burgers vector form tilt walls, whereas arrays of screw dislocations form twist walls. All symmetrically equivalent crystallographic directions and planes which are orthogonal may represent valid glide systems (Roters et al., 2010). For zircon that has tetragonal symmetry, considering two equivalent directions [100] and [010], two relevant orthogonal active glide systems are [100](010) and [010](100) (e.g., Leroux et al., 1999; Reddy et al., 2007; Kaczmarek et al., 2011;). These two relevant glide systems could be labeled as one slip system: $<100>\{010\}$.

\subsection{Motivation and challenge}

This study contributes to basic issues of crystal-plastic deformation mechanisms in zircon. Based on microstructural observations of deformed zircon grains in association with the rock matrix of metaigneous and metasedimentary rocks, the following questions were addressed: is crystal-plastic de- formation of zircon related to dissolution-reprecipitation in fluid presence? Are there differences in zircon behavior in various rock types and at differing metamorphic grade? How do the specific shape and internal heterogeneities of a zircon grain influence its deformation behavior? Which misorientation axes and active slip systems are most common in deforming zircon grains? Does the orientation of the zircon lattice with respect to the external stress field influence the crystal-plastic deformation pattern? How does the nature and microstructure of the local environment (surrounding host phases and adjacent matrix phases) affect the finite deformation pattern of zircon? Which parameters define whether deformed zircon develops a low-angle boundary network or not?

Based on our observations we have classified finite deformation patterns of crystal-plastically deformed zircons and discussed local conditions that facilitate crystal-plastic deformation, as well as possible reasons that define the variety of distortion patterns. 


\section{Geological environment}

General information about samples and presented zircon grains is given in Table 1. Samples were collected from shear zones in two study areas: (1) Western Tauern Window, eastern Alps (amphibolite facies metamorphic grade), and (2) Ivrea-Verbano Zone, southern Alps (granulite facies metamorphic grade).

\subsection{Western Tauern Window, eastern Alps (Zillertal, Tyrol, Austria), amphibolite facies metamorphic grade}

In the Tauern Window (eastern Alps), continental and oceanic rocks of the Penninic and sub-Penninic nappe sequences are exposed, which represent the footwall of the Austroalpine nappe stack. Nappe stacking and predominant metamorphism are related to the closure of the Alpine Neotethys and subsequent continental collision in the Late Cretaceous-Tertiary (Miller et al., 2007). Samples for the present research were collected from the "Zillertaler Kern" lobe of the "Zentralgneis" formation (see Selverstone et al., 1991, and references therein).

The magmatic protholiths of the Zentralgneis formation are uppermost Devonian to lower Permian in age. Three magmatic "pulses" of potassium-rich and calc-alkaline granites, felsic and intermediate volcanites, and tonalitic/granodioritic plutonites can be distinguished (Veselá et al., 2011). The granitoids intruded into pre-Carboniferous, partly poly metamorphic basement rocks consisting of various schists, paraand orthogneisses, amphibolites and meta-ophiolites. In the Zillertal section, Variscan amphibolite facies regional metamorphism has been overprinted at amphibolite-facies metamorphic conditions of $0.5-0.7 \mathrm{GPa}$ and $550-600^{\circ} \mathrm{C}$ at ca. $30 \mathrm{Ma}$ with subsequent greenschist-facies metamorphism (Selverstone, 1985; Pennacchioni and Mancktelow, 2007). Metamorphic (re)crystallization was accompanied by the formation of ductile shear zones (Pennacchioni and Mancktelow, 2007). The sampled shear zones 1 and 2 (see description below) found to the east of Berliner Hütte presumably formed during this latter tectono-metamorphic event.

\subsubsection{Shear zone 1 (lat $47^{\circ} 01^{\prime} 39.308^{\prime \prime} N$, long $11^{\circ} 50^{\prime} 3.669^{\prime \prime} \mathrm{E}$ to lat $47^{\circ} 01^{\prime} 39.987^{\prime \prime} \mathrm{N}$, long $11^{\circ} 50^{\prime} 6.311^{\prime \prime} \mathrm{E}$ )}

The $\sim 50 \mathrm{~m}$ thick ductile shear zone is exposed on the NE slope of the Zemmbach side valley (Sturm and Steyrer, 2003). The shear zone represents strongly foliated quartz-biotite orthogneiss (samples BH12-01-I and BH1202) containing mylonitic layers (sample BH12-01-II) that are leucocratic and depleted in mafic minerals compared to the gneiss. The strongly foliated gneiss is enriched in biotite and white mica (Fig. 1a). The host rock of granitic composition

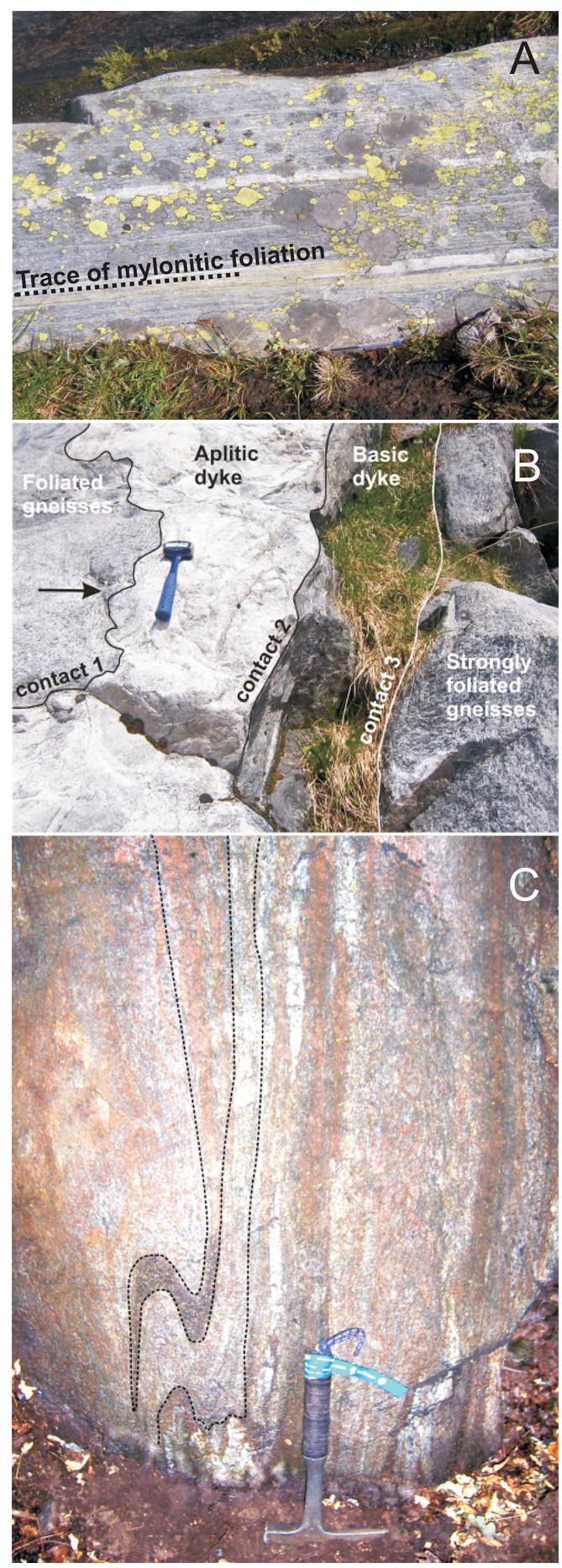

Figure 1. Outcrop photographs. (a) Shear zone 1 in orthogneiss with strong mylonitic foliation. (b) Shear zone 2 with two dykes developed in granitic gneiss. Contact 1 shows a cuspate-lobate structure (black arrow). (c) Shear zone 3, hosting strongly deformed and folded stronalite. Folds of compositional layering are highlighted by the dashed black lines.

is weakly foliated (sample BH12-04) and crosscut by leucocratic veins. 


\subsubsection{Shear zone 2 (lat $47^{\circ} 01^{\prime} 18.129^{\prime \prime} \mathrm{N}$, long $11^{\circ} 50^{\prime} 26.709^{\prime \prime} \mathrm{E}$ )}

A strongly foliated quartz-biotite orthogneiss (sample BH12-06-I and -II) hosts two adjacent deformed dykes, a leucocratic aplitic dyke (sample BH12-08) and a melanocratic, presumably metalamprophyric, dyke (sample $\mathrm{BH} 12-07$ ), as shown in the Fig. 1b. The leucocratic dyke (sample BH1208) shows thickness variations from $20 \mathrm{~cm}$ to $1.5 \mathrm{~m}$ and locally presents a cuspate-lobate structure along the lithological contact 1 (Fig. 1b, arrow). On the lower contact (contact 2, Fig. 1b) with the leucocratic dyke, gneiss is intruded by the mafic dyke (sample BH12-07). The mafic dyke is strongly foliated and folded and apparently accommodates the highest strain intensity, representing the weakest lithology in the sequence. Quartz-biotite gneiss in contact with the mafic dyke (contact 3, Fig. 1b) is also strongly foliated (BH12-06-I). The high-strain zone in gneiss adjacent to contact 3 is about $1 \mathrm{~m}$ thick, whereas the gneiss is less foliated (sample BH12-05) and the shear zone is narrower $(\sim 10 \mathrm{~cm})$ next to contact 1 with the aplitic dyke.

\subsection{Ivrea-Verbano Zone, southern Alps (Forno, Val Strona, northern Italy), granulite facies metamorphic grade}

The Ivrea-Verbano Zone (IVZ) consists of a NE-SWtrending, steeply dipping sequence of metasedimentary and metaigneous basic rocks, ultrabasic mantle tectonites and a large underplated igneous complex. The sequence consists of predominant metasedimentary rocks in the SE and prevailing metabasic rocks and strongly depleted metapelites in the NW. Metamorphism increases progressively from amphibolite facies in the SE to granulite facies in the NW. The IVZ is supposed to represent a section through the lower continental crust that experienced regional metamorphism during the uppermost Paleozoic (Rutter et al., 2007; Quick et al., 2009) and then exhumed towards the upper crust.

Within the IVZ, a network of high-temperature shear zones are observed which are subparallel to the NE-SW elongation direction of the IVZ. The shear zone network extends from Anzola (Val d'Ossola) to Forno (Val Strona) and can be traced for more than $20 \mathrm{~km}$ in length (Brodie et al., 1992). Single shear zones range in width from a few centimeters to more than $10 \mathrm{~m}$, and are rarely as much as $200 \mathrm{~m}$ thick. Mylonites in the northern part of the IVZ completely (re-)equilibrated under granulite-facies conditions prevailing during crustal attenuation/extension and contemporaneous magmatic underplating (Rutter et al., 2007) between 315 and $270 \mathrm{Ma}$ (Rutter et al., 2007; Quick et al., 2009; Sinigoi et al., 2011). In the Val d'Ossola section at Cuzzago, peak $P-T$ estimates are $0.6-1.0 \mathrm{GPa}$ and $>800^{\circ} \mathrm{C}$, based on the peak $P-T$ estimates from the neighboring Val Strona di Omegna (Redler et al., 2012).

\section{Shear zone 3 (lat $45^{\circ} 59^{\prime} 45.64^{\prime \prime} \mathrm{N}$, long $8^{\circ} 21^{\prime} 38.75^{\prime \prime} \mathrm{E}$ )}

The sampling locality near the village of Cuzzago (Val d'Ossola) shows non-foliated metasedimentary granulitefacies rocks, locally known as stronalites (sample IV1206C). Stronalites are crosscut by a discordant layer of sillimanite-biotite-garnet gneiss, which is considered to be a restitic material from partial melting of metapelite (Barboza et al., 1999). Sample material was taken from a severalmeter-thick non-foliated metasediments (Fig. 1c). At the outcrop scale this rock locally has a compositional layering which is folded.

\section{Analytical methods and data representation}

\subsection{Sample preparation}

Zircons were examined in situ using polished thin sections, mechanically prepared with $0.25 \mu \mathrm{m}$ diamond paste, and subsequently chemically polished with alkaline colloidal silica solution (Köstrosol 3530; pH 9.2-10) on an active rotary head polishing machine for $4 \mathrm{~h}$. Samples were cleaned in ethanol and distilled water before carbon coating that was applied to establish electrical conductivity.

Thin sections were cut parallel to the $x-z$ plane (normal to foliation and parallel to lineation); however, it is not always exactly so, for the sample BH12-07 stretching lineation is oblique at about $45-50^{\circ}$ to the thin section cut.

\subsection{Scanning electron microscopy (SEM) and cathodoluminescence $(\mathrm{CL})$ imaging}

All zircons were identified and characterized by backscattered-electron (BSE) and cathodoluminescence (CL) imaging in order to identify the internal microstructures; select areas for FSE imaging, EBSD and Raman analysis; and investigate the host mineral phases, using an FEI Inspect $\mathrm{S}$ scanning electron microscope equipped with a Gatan MonoCL system. Imaging conditions were at $10 \mathrm{kV}$ accelerating voltage, with a CL-image resolution of $1500 \times 1500$ to $2500 \times 2500$ pixels using a dwell time of $80.0-150.0 \mathrm{~ms}$ and probe current/spot size 4.5-5.0.

\subsection{Electron backscatter diffraction (EBSD) analysis and forward-scattered electron (FSE) imaging}

Zircon grains were examined for potential crystal-plastic deformation structures using orientation contrast images (Trimby and Prior, 1999; Prior et al., 1999). These were taken using a forward scattered detector (FSD) mounted on the EBSD tube of an FEI Quanta 3-D FEG instrument (Center of Earth Sciences, University of Vienna, Austria), which is equipped with a Schottky field emission electron source. Electron beam conditions were $15 \mathrm{kV}$ accelerating voltage 
and $2.5-4 \mathrm{nA}$ probe current using the analytic mode. Stage settings were at $70^{\circ}$ tilt and $14-16 \mathrm{~mm}$ working distance. After identification of the potentially deformed grains, EBSD orientation mapping was applied to selected zircon grains. The FEI Quanta 3D FEG instrument is equipped with an EDAX Pegasus Apex 4 system consisting of a Digiview IV EBSD camera and an Apollo XV silicon drift detector for EDX analysis. EDX intensities and EBSD data were collected contemporaneously using the OIM data collection software v6.21. Orientation maps were obtained from beam scanning in hexagonal grid mode at step sizes of $0.1-0.16$ micrometer.

The raw indexing for the entire EBSD maps, including zircon and host phases varies from 70 to $99.7 \%$, depending on the host phase; raw indexing for zircon grains is more than $99.99 \%$. In some cases, after EBSD data collection, the maps were recalculated based on chemical composition of phases using OIM v6.21 software.

The EBSD data are represented in the sample reference frame and presented in two mapping modes. The first mapping mode is false-color-coded misorientation maps, with colors showing the relative angular misorientation of each data point with respect to a user-selected single reference point within the grain (indicated by a red marker); the second mode is local misorientation maps, where each pixel is colored according to the mean misorientation of the respective data point relative to the neighboring points. The orientations of the crystallographic axes are plotted as lowerhemisphere equal area projections and are color-coded according to the corresponding EBSD map of the first mapping mode. The data are usually shown for the whole mapped area of zircon grain if subareas of interest are not specifically indicated. The first mode of maps and pole figures was produced using the EDAX OIM Analysis v6.2.1 software, whereas the second mode of misorientation maps (local misorientation maps) was generated with the MTEX toolbox for MATLAB (Bachmann et al., 2010, 2011; Mainprice et al., 2011). We used MTEX toolbox for plotting histograms of misorientation angles between data points as well as for visualizing the misorientation axis orientation and density contours in inverse pole figures.

The (sub)grain boundaries are visible in 2-D sections as lines, and their traces are characterized by $200-500 \mathrm{~nm}$ wide linear features displayed as low-contrast EBSD pattern data points in the image quality map. We consider misorientation angles between neighboring subgrains ranging from 1 to $10^{\circ}$ to form low-angle boundaries and those higher than $10^{\circ}$ to be high-angle boundaries, as in Piazolo et al. (2012).

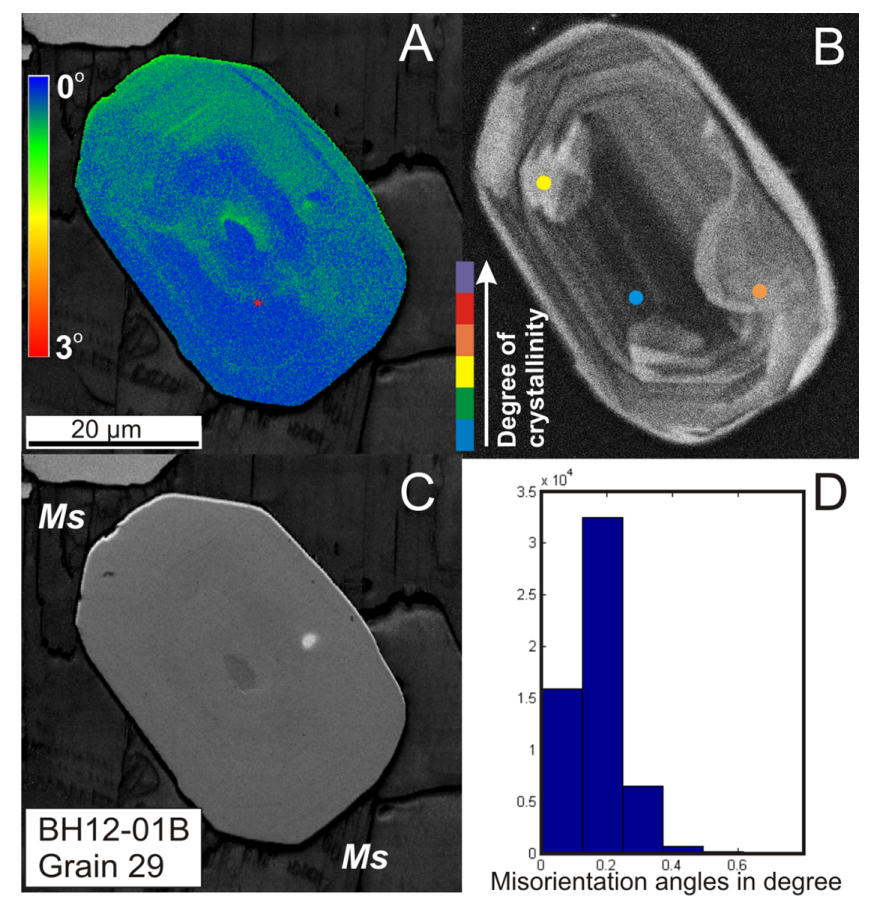

Figure 2. Grain BH12-01B_29, no deformation-related lattice distortion observed. (a) EBSD map color-coded for zircon misorientation (blue-red: $0-3^{\circ}$ ) of each pixel relative to a reference point (red star marker). (b) CL image with colored points representing relative degrees of crystallinity, measured by Raman spectroscopy. (c) EBSD pattern quality map; Ms: muscovite. (d) Histogram of the distribution of misorientation angles between neighboring data points.

\subsection{Raman spectroscopy}

Raman spectra were acquired on a confocal edge filter-based Renishaw RM1000 micro-Raman system equipped with a $50 \mathrm{~mW}$ multimode $\mathrm{Ar}^{+}$laser (using the $488 \mathrm{~nm}$ emission at $\sim 20 \mathrm{~mW}$ ), a grating of 1200 lines per millimeter, and a thermo-electrically cooled CCD detector. Raman intensities were collected with a Leica DMLM microscope with $50 \times / 0.75$ or $100 \times / 0.90$ lenses. These settings resulted in a spectral resolution of $\sim 4 \mathrm{~cm}^{-1}$ and a spatial resolution of better than $\sim 3 \mu \mathrm{m}$. Spectra were recorded for $30 \mathrm{~s}$ in the range from $-50 \mathrm{~cm}^{-1}$ (to get also the Rayleigh line at $0 \mathrm{~cm}^{-1}$ for internal calibration) to $1580 \mathrm{~cm}^{-1}$. Instrument control and basic data processing were done with Grams32 software (Galactic Industries Corp., 1996). Exact peak positions and peak widths (FWHM: full width at half maximum) were extracted (after shift correction according to the Rayleigh line) with PeakFit 4.12 software (SeaSolve Software Inc., 1999-2003).

Raman analyses were used to compare the degree of crystallinity in various zircon grain domains. For this goal a color-coding scale was created based on the range of the 


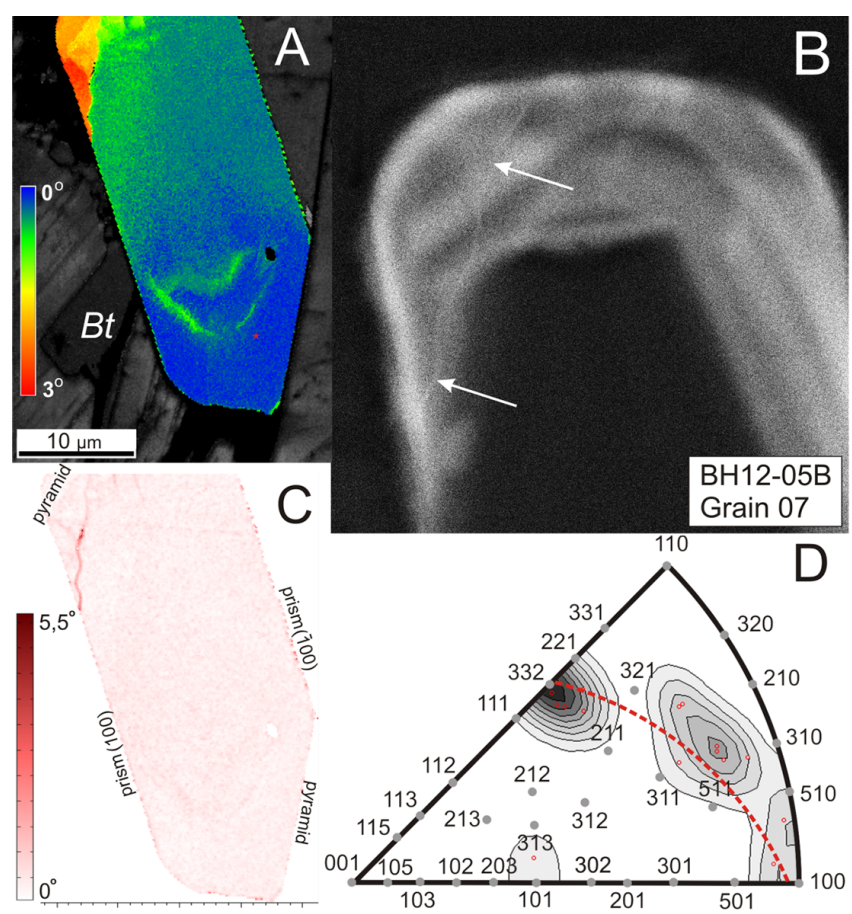

Figure 3. Grain BH12-05B_07, lattice distortion type (III) case 1 . (a) EBSD map color-coded for zircon misorientation with respect to a reference point (red star marker); Bt: biotite. (b) Detailed CL image of the upper part of the grain; bright trace (marked by white arrows) corresponds to subgrain boundary. (c) EBSD map of zircon that shows the orientation changes between neighboring data points ("local misorientation"); labels indicate families of crystallographic faces. (d) Inverse pole figure plot of the misorientation axes distribution density comprising the positions of misorientation axes (small red circles), crystallographic directions (grey dots) and the great circle formed by the misorientation axes (dashed red line).

degree of crystallinity of all analyzed spots. The data points are superimposed as colored dots on CL images.

\section{Petrography and zircon content}

The accessory minerals in lithological descriptions are listed in order from least to most abundant. Microstructural data of zircons from the Western Tauern Window are shown in Figs. 2-9 and 13, and those from the IVZ in Figs. 10-12 and 13. The zircon grain numbers with general information about the sample and shear zone number is presented in Table 1.

\subsection{Shear zone 1}

Data on zircons from shear zone 1 are presented in Figs. 2 and 6-8.

Sample BH12-01-II was collected from an ultramylonitic layer that represents the core of the shear zone and has a sharp contact with the host gneiss even at thin section scale. The ultramylonitic layer is composed of a fine-

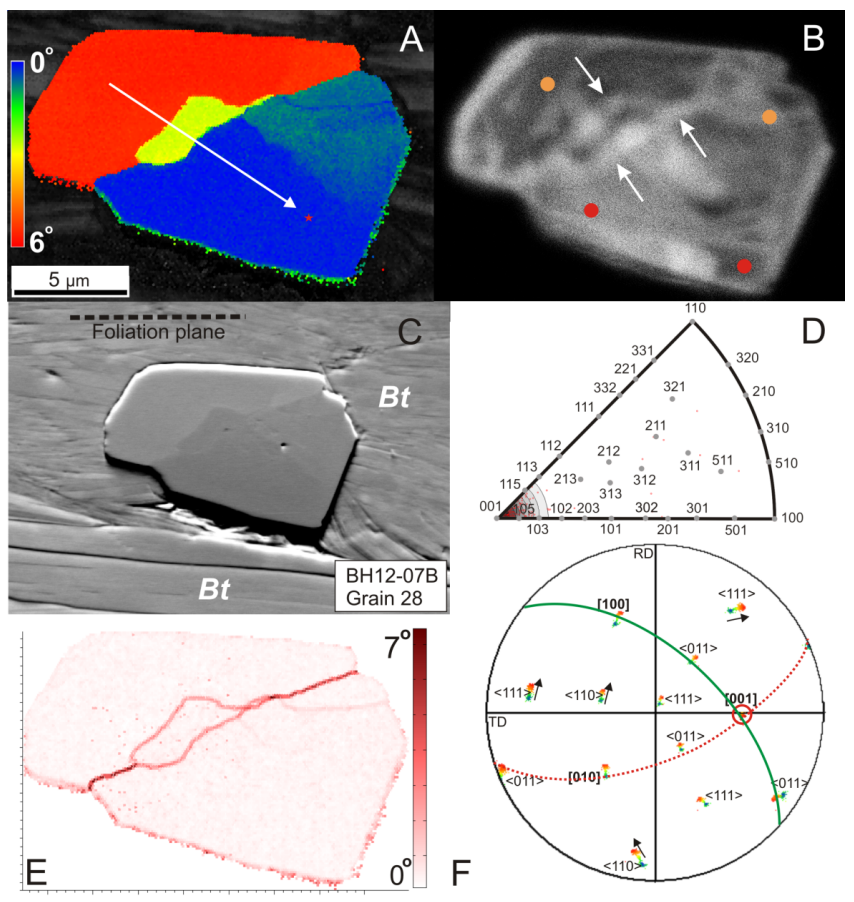

Figure 4. Grain BH12-07B_28, lattice distortion type (III) case 2. (a) EBSD map color-coded for zircon misorientation with respect to a reference point (red star marker). The white arrow corresponds to the misorientation profile shown in Fig. 13c. (b) CL image; the bright lines (marked by white arrows) correspond to the subgrain boundaries; colored points represent relative degree of crystallinity; color coding is as in Fig. 2b. (c) Forward-scattered electron (FSE) image; Bt: biotite. (d) Inverse pole figure plot with the distribution density of misorientation axes shows concentration around zircon [001]. (e) EBSD map of zircon showing the misorientation between neighboring data points. (f) Pole figure plot showing zircon crystal directions (lower-hemisphere equal area projection) color-coded as in (a). Labels indicate the crystallographic directions. Black arrows show scattering of axes due to rotation about zircon [001] (red circle). The dashed red line shows the orientation of the subgrain boundary, and the solid green line indicates the slip plane orientation.

grained, recrystallized plagioclase-quartz matrix (grain size: $70-300 \mu \mathrm{m}$ in diameter, $>95 \mathrm{vol} . \%$ of the layer), with minor modal content of biotite, white mica and epidote $(<5 \%$ in total), which form a weak foliation. Along plagioclase phase boundaries K-feldspar veins a few micrometers thick occur. Zircon, apatite, and titanite are common accessory minerals. Zircon forms small (5-20 $\mu \mathrm{m}$ in diameter) rectangular grains, with aspect ratios from $1: 1$ to $1: 3$. The zircon crystals are characterized by a dark CL signal in the core and a bright thin outer rim (Fig. 6b), where the core has a relatively low degree of crystallinity according to Raman spectroscopy. Two grains from this zone have been analyzed by means of EBSD, and one grain exhibits finite crystal-plastic deformation.

The gneiss from shear zone 1 contains plagioclase, quartz, a large amount of biotite and white mica, and K-feldspar 

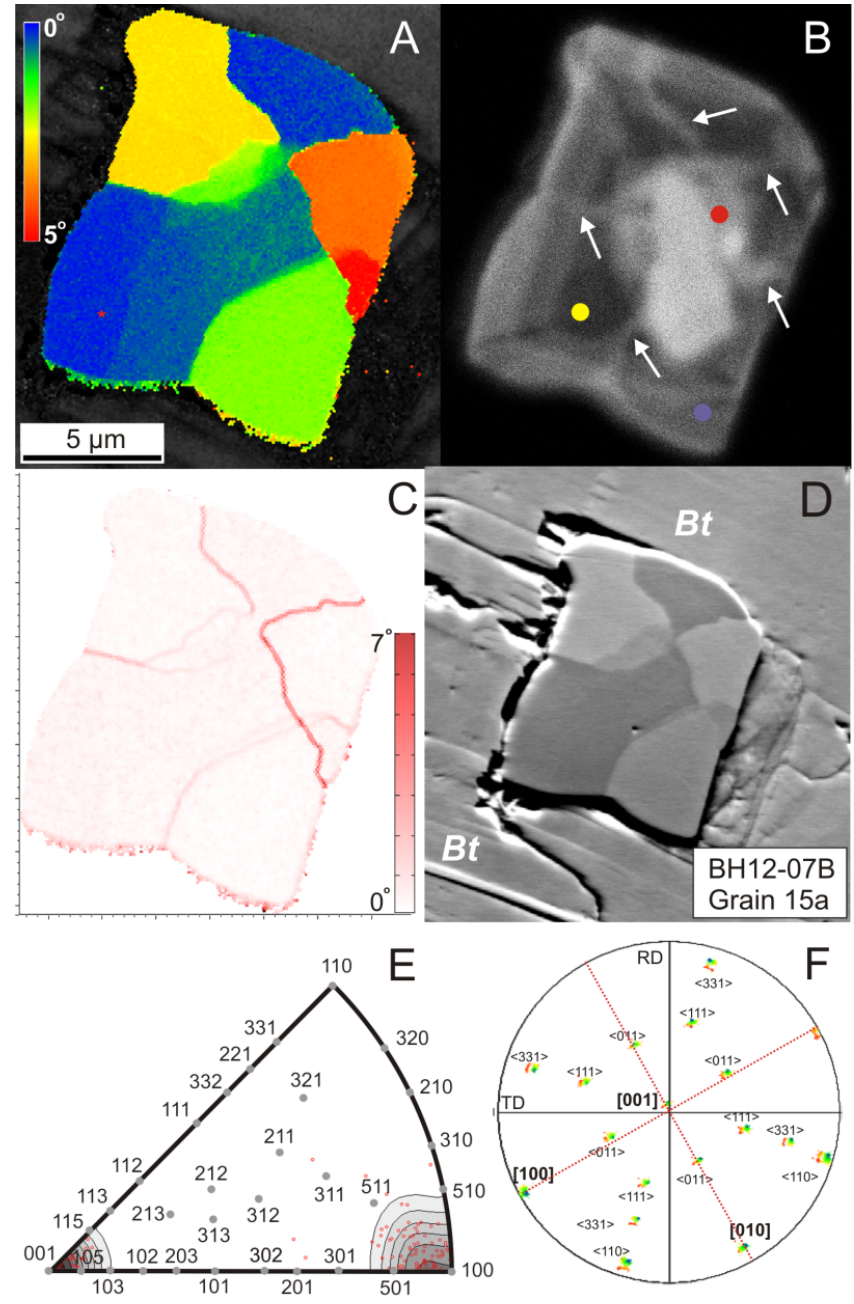

Figure 5. Grain BH12-07B_15a, lattice distortion type (III) case 2. (a) EBSD map color-coded for zircon misorientation with respect to a reference point (red star marker). (b) CL image; bright traces (marked by white arrows) correspond to subgrain boundaries; colored dots represent the relative degree of crystallinity; color coding as in Fig. 2b. (c) EBSD map of zircon showing the misorientation between neighboring data points. (d) Orientation contrast image (FSE); Bt: biotite. (e) Inverse pole figure plot of the distribution density of misorientation axes shows concentrations around $<001>$ and $<100>$. (f) Pole figure plot showing zircon crystal directions (lower-hemisphere equal area projection) colored as in (a). Labels indicate the crystallographic directions. Dashed red lines show the subgrain boundary orientations.

veinlets. Biotite is locally replaced by association of titanite, chlorite, quartz and epidote. The even or sigmoidal foliation is represented by leucocratic layers of plagioclase-quartz and layers consisting of plagioclase, quartz, biotite, white mica and epidote. In some domains the foliation is defined by pure mica bands. Zircons in this sequence have 2 to $50 \mu \mathrm{m}$ grain size and are hosted by plagioclase or biotite grains, sometimes associated with epidote and apatite. The smaller nondeformed grains show oscillatory and sector zoning which is
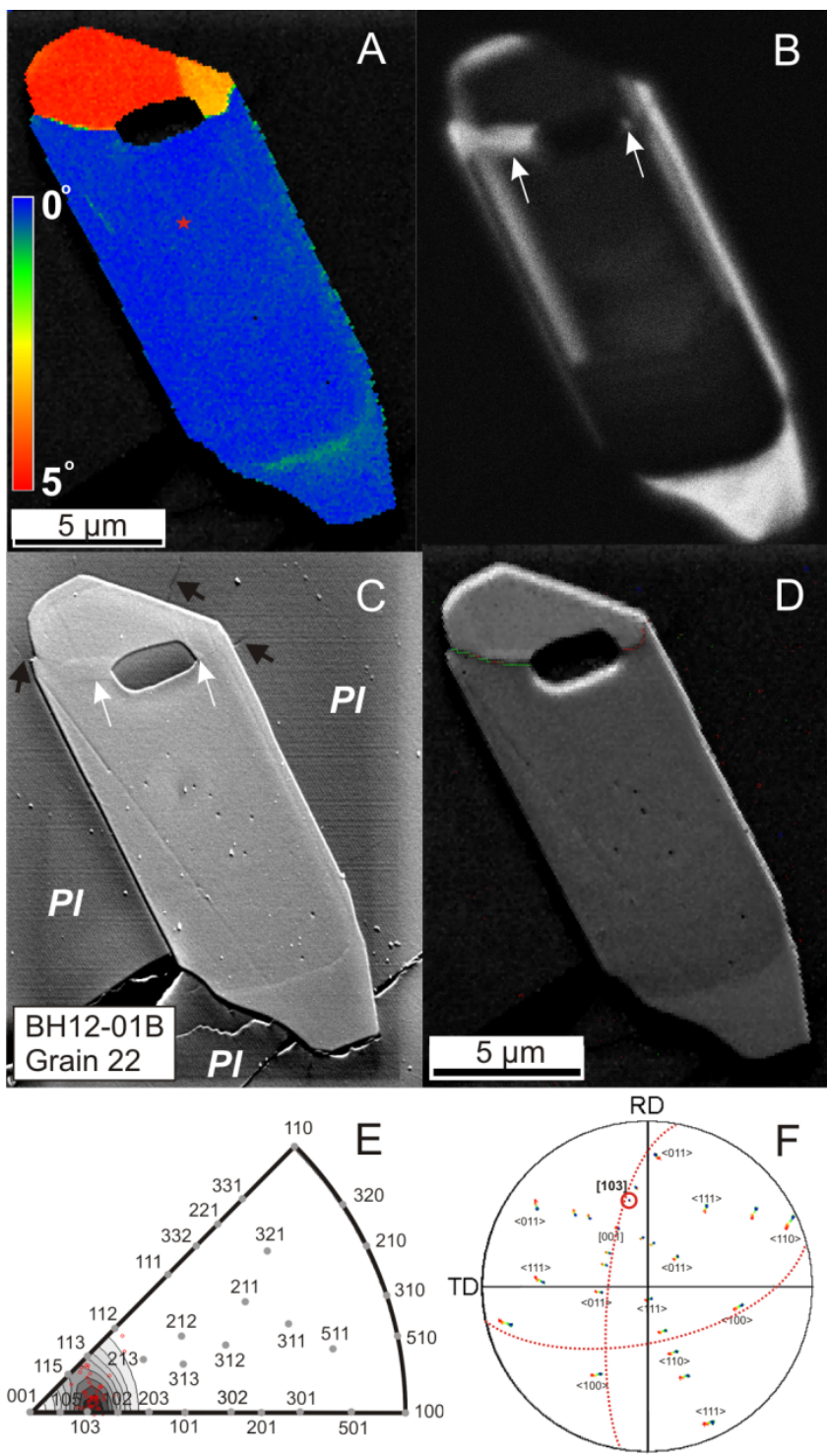

Figure 6. Grain BH12-01B_22 lattice distortion type (III) case 3. (a) EBSD map color-coded for misorientation with respect to a reference point (red star marker). (b) CL image with bright recrystallization zones (shown by white arrows). (c) SE image showing subtle fractures (black arrows) in host plagioclase, and recrystallization zones as in (b) (shown by white arrows); Pl: plagioclase; (d) EBSD pattern quality map showing subgrain boundaries colored for misorientation angles between subgrains (red lines: 2-3 green lines: $3-5^{\circ}$ ). (e) Inverse pole figure plot of the misorientation axes distribution density showing concentration around zircon [103]. (f) Pole figure plot showing zircon crystal directions (lowerhemisphere equal area projection) colored as in (a). Labels indicate the crystallographic directions. Orientation scattering corresponds to rotations around [103] (red circle). Dashed red lines show boundary wall orientations.

truncated by recrystallization zones or marginal overgrowths, which both appear bright in CL images (Fig. 2b). The largest 


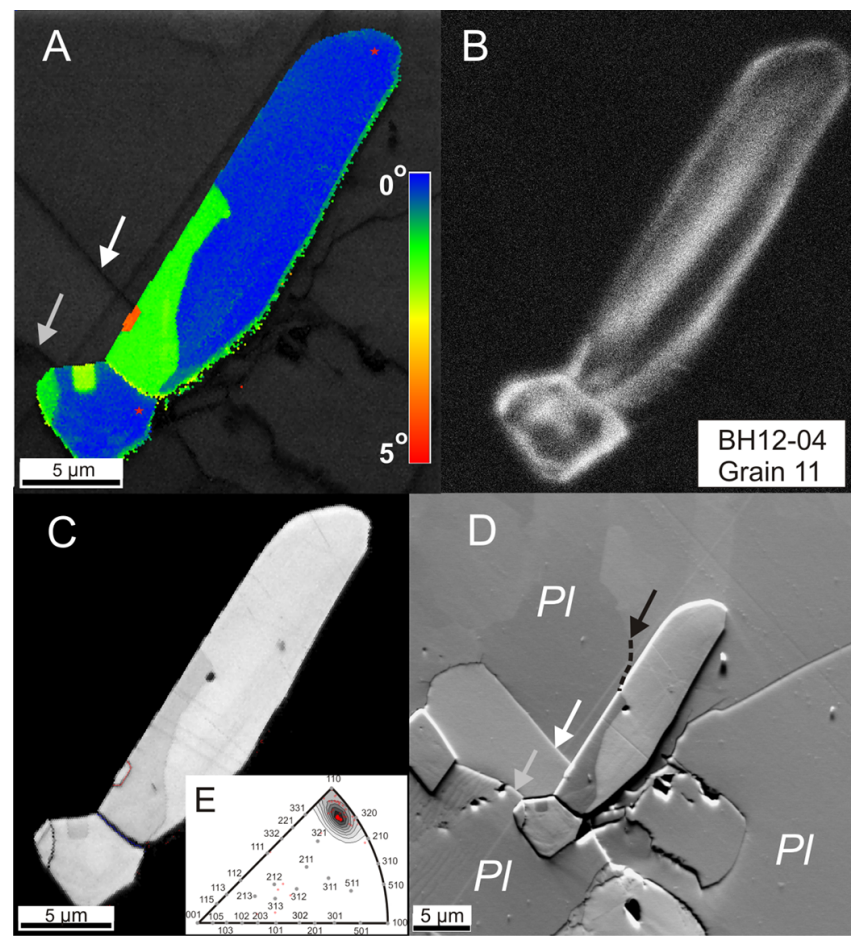

Figure 7. Grain BH12-04_11, lattice distortion type (III) case 4. (a) EBSD map color-coded for zircon misorientation with respect to a reference point (red star marker). Arrows mark plagioclase grain boundary segments. (b) CL image. (c) EBSD pattern quality map with subgrain boundaries colored for misorientation angles between subgrains (red line $=2-5^{\circ}$ ). (d) FSE image; black arrow and dashed line mark plagioclase subgrain boundary; white and grey arrows as in (a); Pl: plagioclase. (e) Inverse pole figure plot of the misorientation axes distribution density showing maxima close to zircon [320].

grains fragmented with rotation of fragments, and sometimes fragments are dispersed in the matrix (Fig. 8).

Samples BH12-01-I and BH12-02-04 are granitic gneisses with varying degrees of deformation. Sample BH12-01-I was taken adjacent to ultramylonitic strongly foliated muscovite-biotite gneiss. Sample BH12-02 exhibits lower deformation intensity than the BH12-01 series. Sigmoidal clasts of plagioclase and quartz in the mylonitic gneiss of sample BH12-02 show top to WSW sense of shear. Samples BH12-03 and BH12-04, collected from the host rock of shear zone 1, are weakly deformed, non-foliated or weakly foliated granitic orthogneisses. A schematic histogram of shear zone 1 showing statistics of cataclastically and plastically deformed grains is presented in Fig. 14a.

\subsection{Shear zone 2}

Data on zircons from the shear zone 2 are presented in Figs. 3-5, 9 and 13.

Sample BH12-05 has no clear foliation and contains large, up to $1 \mathrm{~cm}$ sized, irregularly shaped clusters of biotite grains without shape-preferred orientation. The sample contains several variably oriented small-scale paired shear zones (Pennacchioni and Mancktelow, 2007) adjacent to epidote veins. Samples BH12-05-06 are biotite gneisses compositionally close to samples BH12-01-04. Sample BH12-06I is a strongly foliated gneiss, whereas BH12-06-II represents a biotite gneiss with sigmoidal foliation. Zircon grain size in these lithologies varies from 10 to $100 \mu \mathrm{m}$, with most grains having euhedral shape and oscillatory and sector zoning (Fig. 3b). Some of them represent the fragments of larger preexisting grains.

Sample BH12-07 was collected from a mafic dyke. As the softest lithology in the overall inhomogeneous sequence, the mafic dyke accommodated the highest strain. The sample is chlorite-rich ( $>50 \%$ modal content) due to intense retrogression of biotite. The sample is composed of mafic layers consisting of chlorite, biotite and titanite, with an average thickness of 1-6 mm. Mafic layers alternate with fine-grained plagioclase-quartz layers of the same thickness range. The compositional layering is isoclinally folded. The accessory minerals are calcite, pyrite, zircon, rutile and titanite. Zircon is present as small $(10-30 \mu \mathrm{m})$ euhedral grains with degraded CL zonation. Small xenocrystic cores and oscillatoryzoned rims are sometimes distinguishable in the CL images (Fig. 5b).

Sample BH12-08 is taken from the aplitic dyke. The rock is almost non-foliated and contains only a small fraction of crystal-plastically deformed zircon grains $(8 \%)$; none of these are presented in this paper.

A schematic histogram of shear zone 2 showing statistics on cataclastically and plastically deformed grains is presented in Fig. 14c.

Within shear zones 1 and 2, the initial amphibolite-facies paragenesis is locally replaced by mineral phases that are characteristic for greenschist-facies metamorphic conditions. The association of plagioclase + quartz + biotite is decomposing to K-feldspar + albite + epidote + Al-titanite \pm calcite \pm rutile. Local chlorite pseudomorphs after biotite supposedly represent a retrograde greenschist-facies stage of metamorphism. K-feldspar-, calcite- and epidote-rich veins, as well as some dissolved zircon surfaces and healed fractures decorated by inclusion trails, are evidence of intense fluid infiltration.

\subsection{Shear zone 3}

Data on zircons from the shear zone 3 are presented in Figs. 10-13. A schematic histogram with statistics on shear zone 3 is presented in Fig. 14b. 


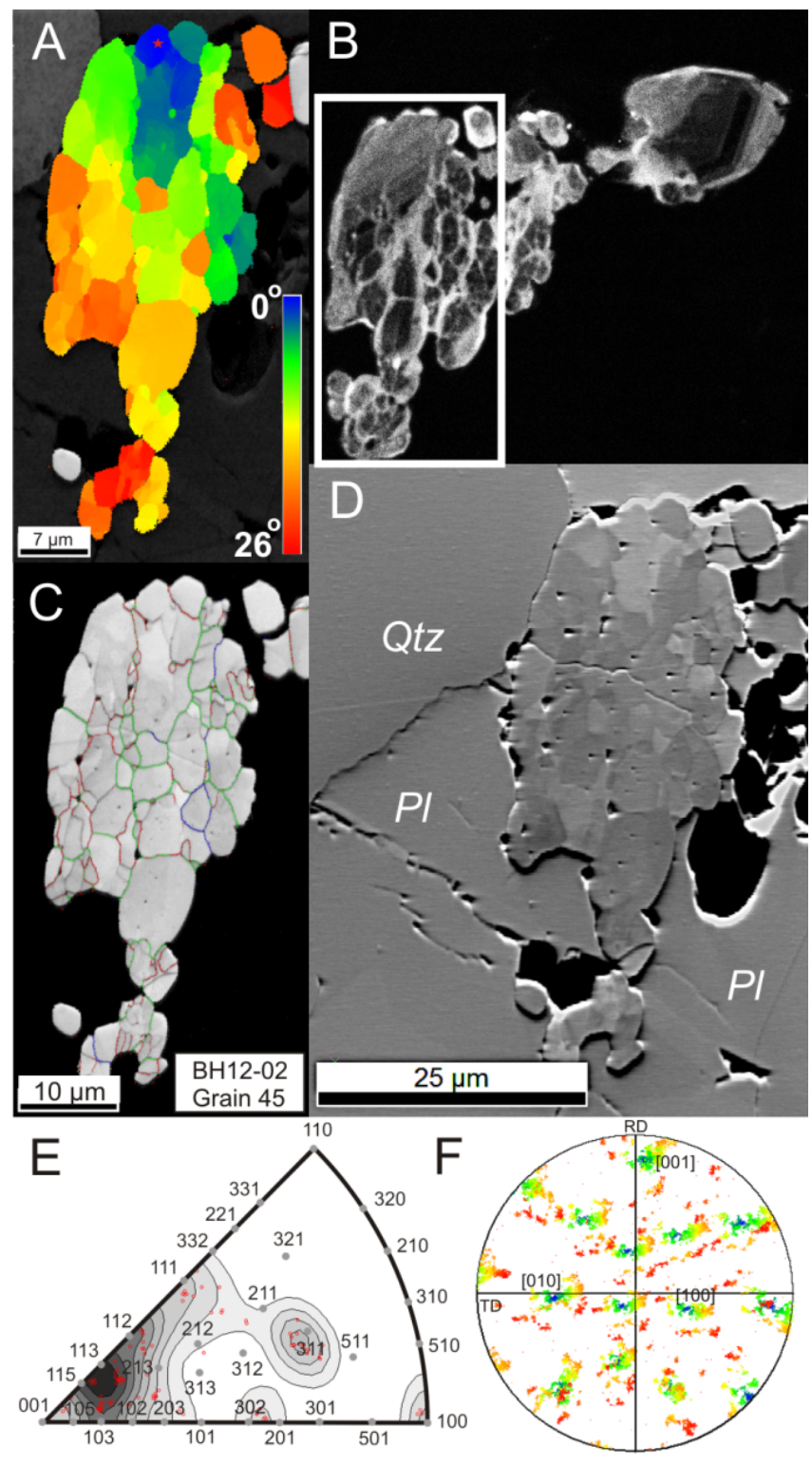

Figure 8. Grain BH12-02_45, lattice distortion type (III) case 5 . (a) EBSD map color-coded for zircon misorientation with respect to a reference point (red star marker). (b) CL image (white rectangle marks position of EBSD map). (c) EBSD pattern quality map with subgrain boundaries colored for misorientation angles between subgrains (red: $2-5^{\circ}$; green: $5-15^{\circ}$; blue: $>15^{\circ}$ ). (d) FSE image; Qtz: quartz; Pl: plagioclase. (e) Inverse pole figure plot of the misorientation axes distribution density. (f) Pole figure plot showing zircon crystal directions (lower-hemisphere equal area projection) colored as in (a). Labels indicate the crystallographic directions.

Sample IV12-06C is representative of shear zone 3 from the IVZ. It is a massive rock consisting of large garnet grains $(0.5-5 \mathrm{~mm}$ in diameter) that are fractured and have an irregular shape. Locally, garnet forms aggregates of smaller grains sized from 40 to $80 \mu \mathrm{m}$ that form a foliation pattern. The space between the garnet clasts is filled with Mg-rich biotite

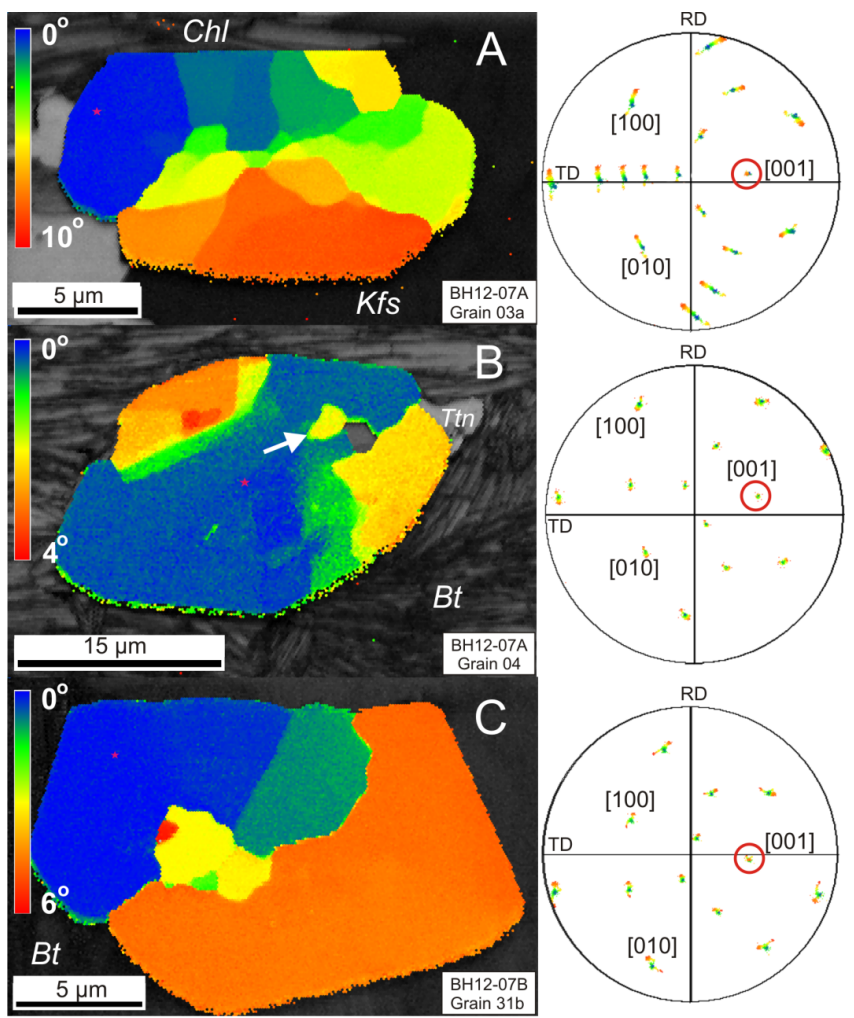

Figure 9. (Sub)grain shape and crystallographic orientation of zircon from sample BH12-07 (basic dyke). Left-hand side - EBSD maps colored for misorientation with respect to a single reference point (red star marker); right-hand side - pole figure plots showing zircon crystal directions (lower-hemisphere equal area projection) colored as in the corresponding EBSD map. Rotation axes parallel to zircon [001] axis are highlighted by a red circle. (a) Grain BH12-07A_03a, lattice distortion type (III) cases 2 and 4. (b) Grain BH12-07A_04, lattice distortion type (III) cases 1, 2, and 3. Arrow highlights subgrain adjacent to the mineral inclusion. (c) Grain BH12-07B_31B, lattice distortion type (III) case 2. Bt: biotite; Chl: chlorite; Kfs: K-feldspar; Ttn: titanite. NB: the thin sections were cut normal to the foliation plane and at an angle of $50^{\circ}$ with respect to the intersection lineation so that the zircon [001] direction coincides with the intersection lineation and the fold axis.

(phlogopite), quartz and plagioclase. These phases occur in two grain sizes: $100-250 \mu \mathrm{m}$ and below $10 \mu \mathrm{m}$. Plagioclase and biotite sometimes form thin symplectic intergrowths. The zircons range from 20 to $50 \mu \mathrm{m}$ in diameter and mostly have a roundish shape. Zircon grains form inclusions within garnet but more often occur in the plagioclase-quartz matrix. In CL images they contain a dark core and a thick bright homogeneous rim (Fig. 10b). Around $13 \%$ of grains investigated for orientation contrast appeared crystal-plastically deformed, and $32 \%$ appeared to be deformed cataclastically. Only irregularly shaped grains display crystal-plastic deformation (Figs. 10,12), and they are found in the domains with large-grained garnet. 


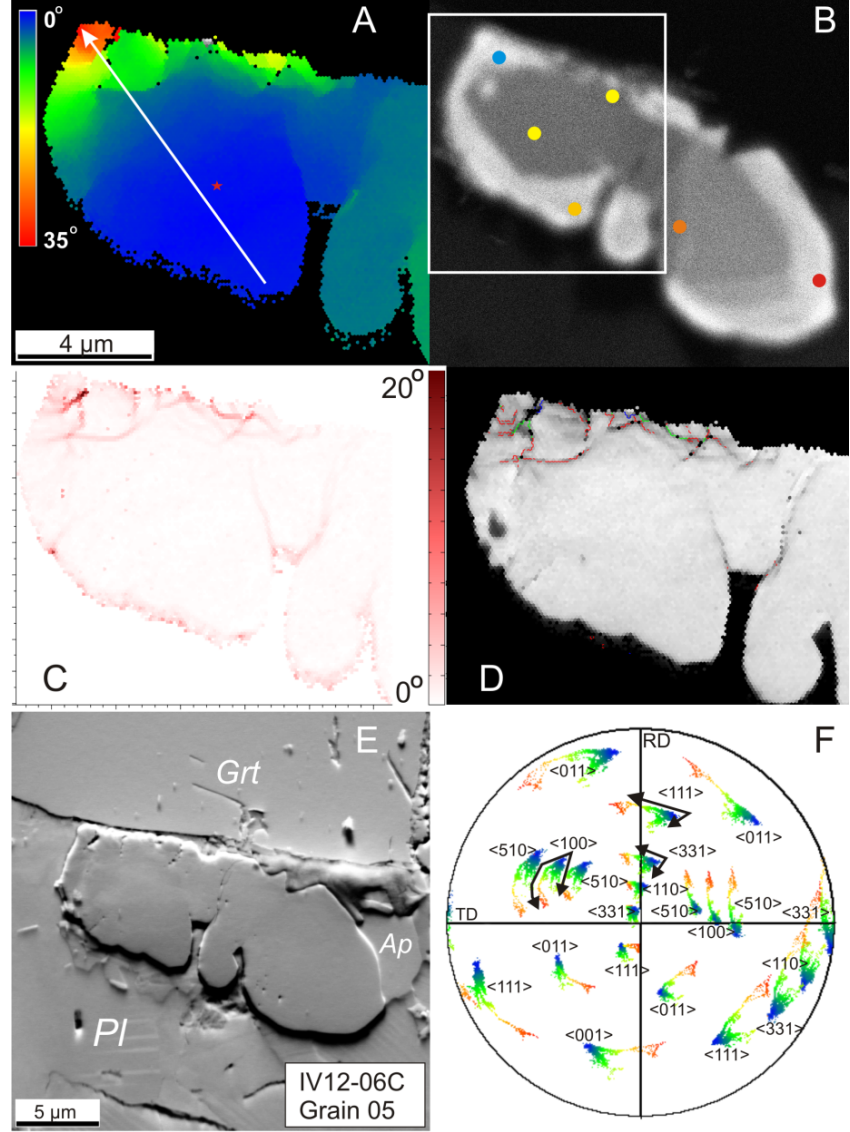

Figure 10. Grain IV12-06C_05, lattice distortion type (II). (a) EBSD map color-coded for zircon misorientation with respect to a reference point (red star marker), the white arrow corresponds to the misorientation profile shown in Fig. 13b. (b) CL image; colored points represent relative degree of crystallinity; color coding as in Fig. 2b. The EBSD map position is marked by the white rectangle. (c) EBSD map of zircon showing the misorientation between neighboring data points. (d) EBSD pattern quality map with subgrain boundaries color-coded as in Fig. 8c. (e) FSE image; Grt: garnet; Pl: plagioclase; Ap: apatite. (f) Pole figure plot showing zircon crystal directions (lower-hemisphere equal area projection) colored as in (a). Labels indicate the crystallographic directions. Black arrows indicate split in the direction of axes rotation.

\section{Microstructural and crystallographic orientation data}

With respect to the rheological properties of zircon and its host phases, and to characterize the difference in viscosity between them, we will try to avoid ambiguous terms and will refer to minerals that have low viscosity and are rheologically weaker than zircon (like biotite and chlorite) as "soft" phases, and to the phases that have higher viscosity and are rheologically stronger than zircon or relevant to it (like garnet and plagioclase) as "strong" phases.

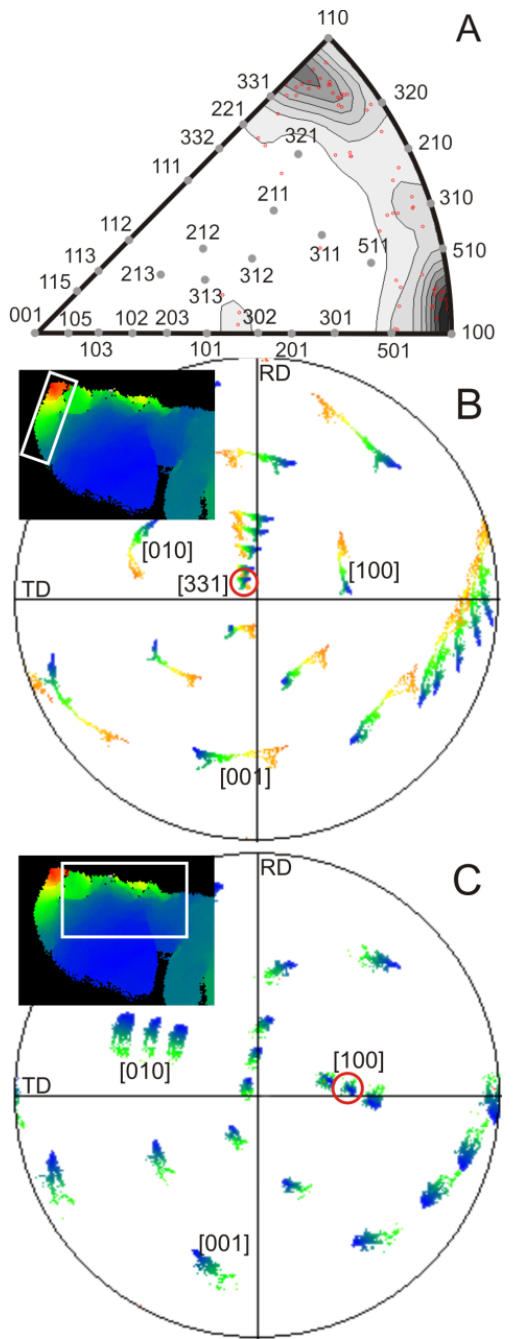

Figure 11. Orientation and misorientation data of grain IV1206C_05, lattice distortion type (II). (a) Inverse pole figure plot of the misorientation axes distribution density, showing axes concentrated parallel to [331] and [100] axes. (b) and (c) show pole figure plot showing crystal directions (lower-hemisphere equal area projection) of two deformed parts of the grain (indicated by a white rectangle in the inset), colored as in insets. Misorientation axes are highlighted by the red circle.

\subsection{CL-bright domains}

Grains with CL-bright domains that truncate oscillatory zoning were investigated with orientation mapping in order to establish the relationships between dissolution-reprecipitation and crystal-plastic deformation in zircon.

The characteristic feature of zircon grains in granitic gneisses from shear zones 1 and 2 is that CL-bright domains truncate initial oscillatory zoning. CL-bright domains often form several mutually crosscutting generations within a single grain. Grain 29 (Fig. 2a-c) from sample BH12-01I shows semicircular CL-bright intragranular domains with 


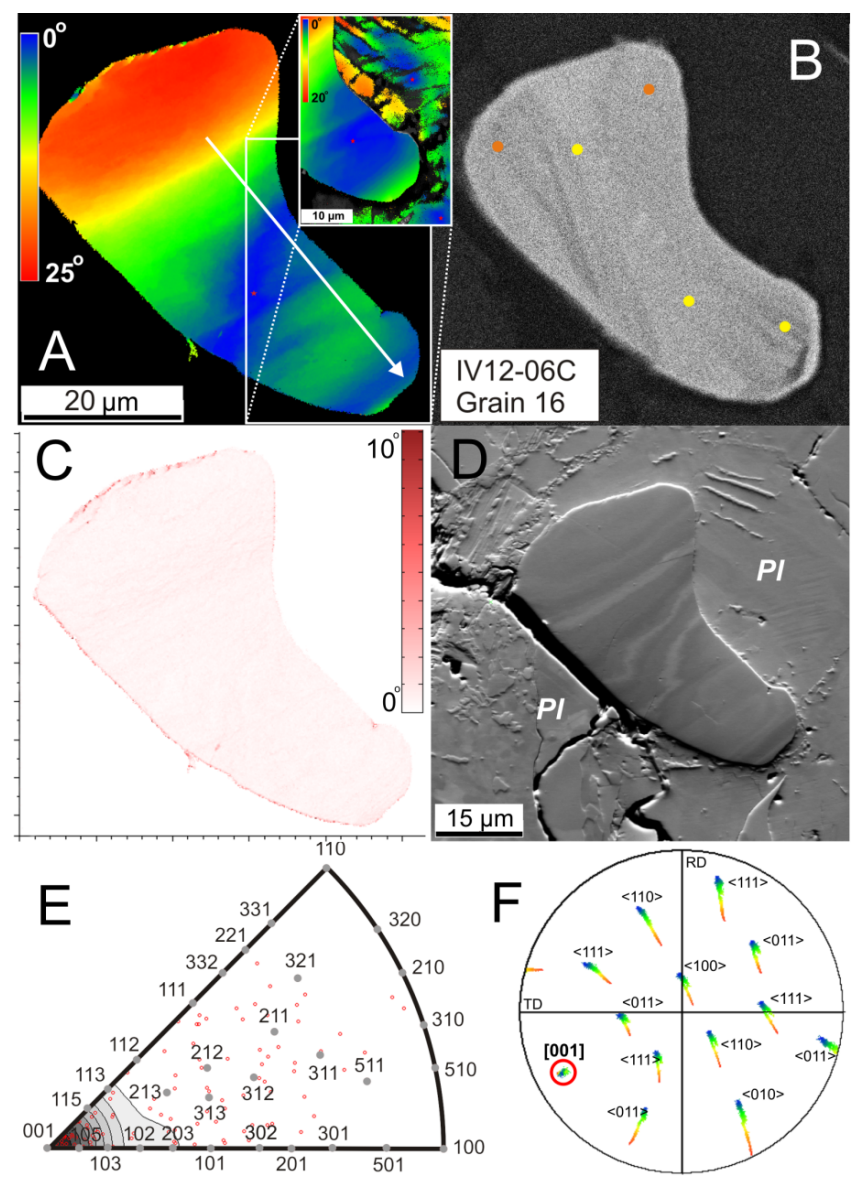

Figure 12. Grain IV12-06C_16, lattice distortion type (I). (a) EBSD map color-coded for zircon misorientation with respect to a reference point (red star marker); white arrow corresponds to misorientation profile shown in Fig. 13a. Inset - color-coded EBSD map that includes misorientation of host plagioclase, showing lattice rotation up to $20^{\circ}$. (b) CL image; colored points represent relative degree of crystallinity; color coding as in Fig. 2b. (c) EBSD map of zircon showing the misorientation between neighboring data points. (d) FSE image; Pl: plagioclase. (e) Inverse pole figure plot of the misorientation axes distribution density. (f) Pole figure plot showing zircon crystal directions (lower-hemisphere equal area projection); colored as in (a). The red circle indicates rotation axis.

smooth or ragged domain boundaries (Fig. 2b). CL-bright domains lack significant misorientation with respect to the remaining grain, showing orientation variations of less than $0.5^{\circ}$ (Fig. 2a, d). Raman spectroscopy documented an increased degree of crystallinity of the CL-bright domains (Fig. 2b).

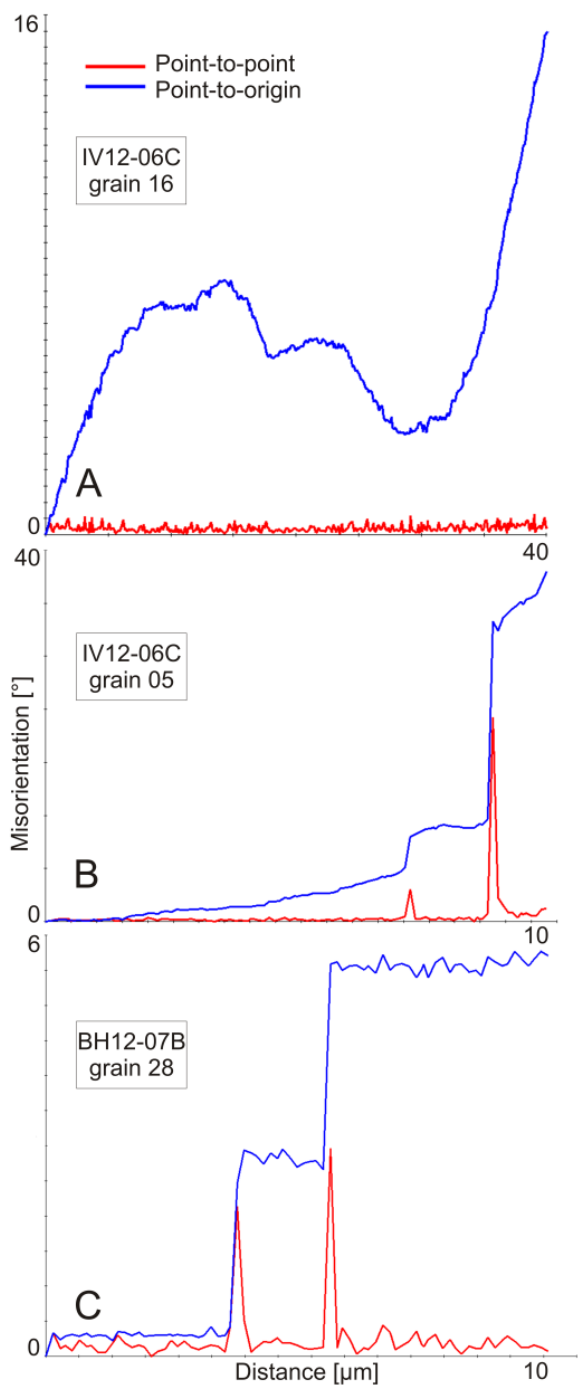

Figure 13. Misorientation profiles of zircon showing point-topoint (red line) and point-to-origin (blue line) misorientations for (a) grain IV12-06C_16, displaying spatially continuous lattice rotation (for location of the profile line see Fig. 12a). (b) Grain IV1206C_05, showing subgrain boundary formation together with spatially continuous lattice distortion (for location of the profile line see Fig. 10a). (c) Grain BH12-07B_28, exhibiting subgrain formation (for location of the profile line see Fig. 4a).

\subsection{Zircon finite lattice distortion types}

Crystallographic orientation maps show intragranular orientation variations within some of the zircon grains. Three main types of lattice distortion patterns were distinguished in plastically deformed zircon grains (see Table 2), based on the absence (type I) or presence (type II and III) of well-developed subgrain boundaries in strained zircon grains. Distortion pattern type (I) is characterized by gradual lattice rotation without any subgrain boundaries formation. Type (II) contains half-circular shaped subgrain boundary traces with high 
Table 2. Types of finite deformation patterns with examples from the present study and from the literature. Groups characterizing type (III) lattice distortion describe different mechanisms for the finite deformation pattern formation observed.

\begin{tabular}{|c|c|c|c|c|c|}
\hline \multicolumn{2}{|c|}{$\begin{array}{l}\text { Type (I): gradual bending, } \\
\text { no subgrain boundaries }\end{array}$} & \multicolumn{2}{|c|}{$\begin{array}{l}\text { Type (II): both gradual bending and } \\
\text { subgrain boundaries }\end{array}$} & \multicolumn{2}{|l|}{ Type (III): network of low-angle boundaries } \\
\hline Description & Examples & $\begin{array}{l}\text { Description and } \\
\text { conditions }\end{array}$ & Examples & Description and conditions & Examples \\
\hline \multirow{5}{*}{$\begin{array}{l}\text { Free dislocation } \\
\text { density, gradual } \\
\text { bending of the } \\
\text { grain, misorien- } \\
\text { tation axes par- } \\
\text { allel to [001] or } \\
\text { [100]. }\end{array}$} & \multirow{5}{*}{$\begin{array}{l}\text { IV12-06C_16 } \\
\text { (Fig. 12); } \\
\text { "type (I) lattice dis- } \\
\text { tortions" in Piazolo } \\
\text { et al. (2012); BP03/3 } \\
\text { in MacDonald et al. } \\
\text { (2013); LG-2a Grain 17 } \\
\text { in Moser et al. (2009); } \\
\text { area A in Reddy et al. } \\
\text { (2007); zircon } 5 \text { from } \\
\text { 73215,122 in } \\
\text { Timms et al. (2012b). }\end{array}$} & \multirow{5}{*}{$\begin{array}{l}\text { Local deformation of } \\
\text { the rim(s) due to colli- } \\
\text { sion of crystals/mineral } \\
\text { grains or deformation } \\
\text { within fine-grained ma- } \\
\text { trix; presence of two } \\
\text { or more misorientation } \\
\text { axes often observed. In- } \\
\text { homogeneous pressure } \\
\text { distribution required. }\end{array}$} & \multirow{5}{*}{$\begin{array}{l}\text { IV12-06C_05 (Figs. } 10 \\
\text { and 11); } \\
\text { "type (II) lattice distortions" in } \\
\text { Piazolo et al. (2012); GG09/1 } \\
\text { in MacDonald et al. (2013); } \\
\text { area B and C in Reddy et al. } \\
\text { (2007); grain from GST15 } \\
\text { (area A) in Timms et al. } \\
\text { (2006) and Timms and Reddy } \\
\text { (2009); grains } 5 \text { and } 8 \text { from } \\
\text { Jhs2PON4, Timms and Reddy } \\
\text { (2009). }\end{array}$} & $\begin{array}{l}\text { Case } 1 \\
\text { Deformation of specific grain domains. Fa- } \\
\text { vorable shape orientation in the local stress } \\
\text { field; decoupling from the matrix. }\end{array}$ & $\begin{array}{l}\text { BH12-05B_07 (Fig. 3); } \\
\text { DP02/7 in MacDonald et al. (2013); V09-237 G4 in } \\
\text { Moser et al. (2011); UX in Timms and Reddy (2009). } \\
\text { Possibly Reddy et al. (2009). }\end{array}$ \\
\hline & & & & $\begin{array}{l}\text { Case } 2 \\
\text { Activation of dominant slip system(s). Fa- } \\
\text { vorable crystallographic orientation in the } \\
\text { local stress field and rheologically weaker } \\
\text { host phase required. }\end{array}$ & $\begin{array}{l}\text { BH12-07A_03a (Fig.99), BH12-07B_15a (Fig. 5), } \\
\text { BH12-07B_26 (Fig. 9c), BH12-07B_28 (Fig. 4), } \\
\text { BH12-07B_31b (Fig. 9b). Type of distortion: (III) in } \\
\text { Piazolo et al. (2012). }\end{array}$ \\
\hline & & & & $\begin{array}{l}\text { Case } 3 \\
\text { Low-angle boundaries emanating from } \\
\text { mineral inclusion. Internal heterogeneity } \\
\text { required. }\end{array}$ & $\begin{array}{l}\text { BH12-01B_22 (Fig. 6). BH12-07A_04 (Fig. 9b); } \\
\text { Timms et al. (2012a). }\end{array}$ \\
\hline & & & & $\begin{array}{l}\text { Case } 4 \\
\text { Depends on the configuration of the host } \\
\text { phases; coupling with the matrix required. }\end{array}$ & $\begin{array}{l}\text { BH12-04_11 (Fig. 7), BH12-07A_03a (Fig. 9a); } \\
\text { BP06/3 in MacDonald et al. (2013) (?). }\end{array}$ \\
\hline & & & & $\begin{array}{l}\text { Case } 5 \\
\text { Brittle deformation, sometimes followed by } \\
\text { the crack healing. }\end{array}$ & $\begin{array}{l}\text { BH12-02_45 (Fig. 8); } \\
\text { Rimsa et al. (2007). }\end{array}$ \\
\hline
\end{tabular}

misorientation (more than $10^{\circ}$ ), whereas type (III) shows continuous low-angle boundary networks (less than $10^{\circ}$ misorientation). Our classification of lattice distortion patterns is consistent with that suggested by Piazolo et al. (2012), but it is more generalized.

Type (I) and (II) patterns are predominant in granulitefacies rocks, whereas type (III) is more common in the amphibolite-facies rocks (Fig. 14a-c). Examples of each distortion type are presented below.

\subsubsection{Distortion pattern type (I)}

Grain IV12-06C_16 is hosted by a polycrystalline plagioclase aggregate. The grain is elongated normal to its $c$ axis and has an anhedral shape with a smoothly curved boundary trace (Fig. 12). It shows a high grain-internal deformation that amounts to $25^{\circ}$ intragranular orientation variation, but forms no (sub)grain boundaries (Fig. 12a, c). The EBSD mapping of host polycrystalline plagioclase reveals gradual lattice rotation that reaches the misorientation up to $20^{\circ}$ with respect to the reference point (Fig. 12a, inset). The orientation of zircon gradually changes by about $0.6-1.8^{\circ}$ per micrometer (Fig. 13a), and so the misorientation between single points within the grain does not reveal any distinguishable features (Fig. 12c). The orientation contrast image displays an undulatory pattern (Fig. 12d). The CL image has a uniformly bright signal without strong zoning or mantle-core structure, and the degree of crystallinity does not change significantly across the crystal (Fig. 12b). Misorientation data demonstrate a scattered distribution of the misorientation axis with a higher density close to zircon [001]; however, the pole figure shows clear lattice rotation around zircon [001] (Fig. 12e, f).

\subsubsection{Distortion pattern type (II)}

Domain IV12-06C_05 is situated at the phase boundary between a polycrystalline plagioclase aggregate and a single garnet grain (Fig. 10e). The zircon aggregate has an irregular shape with curved boundaries and shows significantly higher intragranular orientation variations than grains with type (I) and (III) structures, reaching $35^{\circ}$ (Fig. 10a). However, the misorientation is almost indistinct in the FSE orientation contrast image (Fig. 10e). Unlike the lattice distortion type (I), type (II) demonstrates (sub)grain boundary formation developed within distorted zircon rims. (Sub)grain boundaries have a half-circular open shape with the convex side facing towards the undistorted grain domains (Fig. 10d). Subgrain boundaries occur locally, terminating within the grain, and are coupled with a gradual bending of the rim (Fig. 13b). The point-to-origin misorientation profile of deformed grains shows gradual distortion between subgrain boundaries and sharp steps when crossing them (Fig. 13b). A few grain boundaries are presented (Fig. 10d, green and blue contours), indicating formation of the new zircon grains next to the garnet-zircon boundary. The CL image (Fig. 10b) yields a dark core and bright rim. The degree of crystallinity is decreased in the strained domain with respect to the rest of the grain (Fig. 10b, colored dots) consistent with an increase of local misorientation angles (Fig. 10b). The pole figure shows a complex rotation pattern of the crystallographic axes. The rotation trend splits into two major parts (Fig. 10f, black arrows). Lattice rotation along a profile normal to the zircon/garnet boundary yields misorientation axes clustered around zircon [331], whereas the lattice portion parallel to the phase boundary yields a misorientation axis around the zircon [100] (Fig. 11b, c). This is consistent with the misorientation axes distribution density plot that demonstrates two 


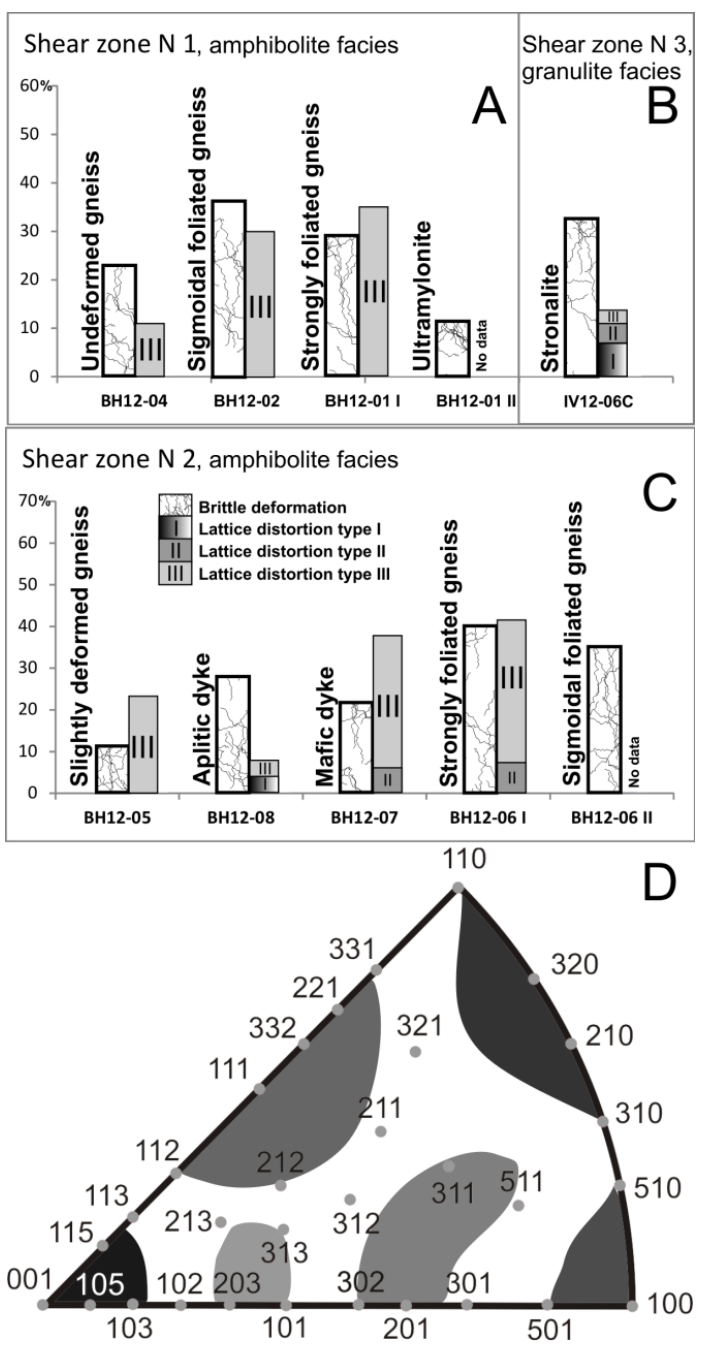

Figure 14. (a) Histogram representing the percentage of deformed zircon grains in each sample in the profile across amphibolite shear zone 1 . The succession of rocks is from less deformed to mylonitized. (b) Histogram representing the percentage of deformed zircon grains in granulite shear zone 3. (c) Histogram representing the percentage of deformed zircon grains in each sample in the profile across amphibolite shear zone 2. The succession of the rocks is equivalent to Fig. 1b. (d) Collective misorientation axes distribution density plot based on 60 analyzed grains from different lithologies. The intensity of the grey shading is proportional to the misorientation axes density.

density peaks for misorientation axes that are at a mutual angle of about $45^{\circ}$ clustering around [331] and close to [100] (Fig. 11a).

\subsubsection{Distortion pattern type (III)}

A large variety of grains with distortion pattern type (III) have been found in amphibolite-facies shear zones. Several deformed grains are described in this study; their lattice distortion pattern was conditioned by local environment.

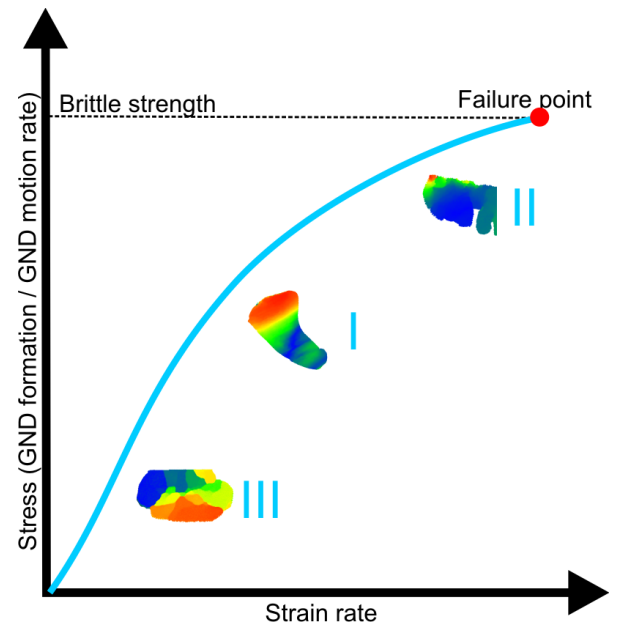

Figure 15. Schematic diagram for different finite crystal-plastic deformation patterns in zircon that are stress-strain rate dependent. I-III reflect deformation pattern types (I), (II) and (III), respectively. GND: geometrically necessary dislocations.

Grain BH12-05B_07 (Fig. 3) is hosted by a biotite aggregate. Zircon grain has an elongated idiomorphic and almost elliptical shape and shows lattice distortion on its upper left portion, reaching a maximum intragranular misorientation of about $3^{\circ}$. The subgrain boundary appears in the CL image (Fig. 3b) as a thin bright linear feature truncating the oscillatory zoning, and also forms curved traces in the EBSD map (Fig. 3a, c). The misorientation axes are arranged along a great circle in the inverse pole figure plot (dashed line in Fig. 3d). The curved trace of a subgrain boundary (Fig. 3a-c) and the distribution of misorientation axes along the great circle (dashed line in Fig. 3d) are the features of cross slip (Poirier, 1985; Reddy et al., 2007), which in this case results from the activity of different slip planes, e.g., zircon (332), (321), (510) and (100) (Fig. 3d).

Grain BH12-07B_28 (Fig. 4) is hosted by biotite and has a short-prismatic euhedral shape (Fig. 4c). Zircon grain is decoupled from the host biotite, which could be concluded from normal and reverse drag of the surrounding biotite and by the void parallel to the lower face of the grain (Fig. 4c). The grain shows maximum intragranular orientation variations of $6^{\circ}$ (Fig. 4a, e). Misorientation profile shows sharp peaks for point-to-point misorientation and steps for misorientation with respect to a single reference point when crossing traces of subgrain boundaries (Fig. 13c). The subgrain boundaries stretch from lower left to upper right (Fig. 4a-c, e), and their traces extend in $\mathrm{C}^{\prime}$ geometry with respect to the mylonitic foliation. Subgrain boundaries appear bright in the CL image (Fig. 4b, white arrows). The degree of crystallinity does not vary significantly across the grain (Fig. 4b). Crystallographic orientation data of zircon show a clear concentration of the misorientation axes around the zircon [001] ( $c$ axis), consistent with the crystal axes rotation along small 
circles around the undispersed cluster of zircon [001] direction (Fig. 4d, f).

Grain BH12-07B_15a (Fig. 5) from the same sample is also surrounded by biotite and has a rectangular, shortprismatic shape. Grain is decoupled from the matrix, as there is a void parallel to the left, upper and lower zircon faces, and along the right face there is recrystallized biotite aggregate. The EBSD map shows an intragranular orientation variation of $5^{\circ}$. The grain contains a network of approximately orthogonal subgrain boundaries (Fig. 5a-d). These separate distinct subgrains with clear orientation contrast (Fig. 5d) and appear bright in the CL image (Fig. 5b, white arrows). Within the grain, a CL-bright xenocrystic core is observed. Some subgrain boundaries intersect this core domain; others terminate at its boundary (Fig. 5b, c, upper part of the grain). Concentric growth zones show an increasing degree of crystallinity towards the rim (Fig. 5b). The misorientation axes inferred from misorientations of the subgrains are parallel to zircon [001] and [100] (Fig. 5e), whereas the crystal axes show asterism (Fig. 5f).

Grain BH12-01B_22 (Fig. 6), from the ultramylonite core of shear zone 1 , is located in plagioclase, has elongated euhedral shape and displays subgrain boundaries emanating from mineral inclusion (Fig. 6a). Subtle fractures in the host plagioclase (Fig. 6c, black arrows) intersect the zircon phase boundary at the positions close to those of the zircon subgrain boundary intersects. The CL image reveals not only a dark core and a bright outer rim but also a linear CL-bright zone that is spatially associated with a subgrain boundary (Fig. 6b, white arrows). The misorientation axes cluster close to zircon [103] (Fig. 6e) in accord with crystallographic axes that are rotated around the [103] direction (Fig. 6f).

Scan BH12-04_11 (Fig. 7) covers two idiomorphic zircon grains that are hosted by polycrystalline plagioclase (Fig. 7d). One of the zircon grains has an elongated shape with an aspect ratio of $1: 5$ in the 2-D section, whereas another is rather isometric. The elongated grain shows graininternal orientation variations of about $5^{\circ}$ due to the presence of subgrains, which show strong orientation contrast although subgrain boundaries do not appear in the CL image (Fig. 7a, b and d). Within the subgrains orientation variations are negligible. The grain boundary trace of fine-grained plagioclase at the left (Fig. 7a, d, white arrow) is oriented at a high angle to the trace of the zircon prismatic face. The coarser plagioclase grain covering the upper left of the map shows grain-internal orientation contrast, and a plagioclase subgrain boundary trace oblique to the zircon prismatic face (Fig. 7d, black arrow, dashed line). The plagioclase (sub)grain boundaries impinge on the zircon phase boundary at the same sites as the subgrain boundaries within the zircon. The misorientation axes show a maximum parallel to zircon [320] (Fig. 7e).

Domain BH12-02_45 (Fig. 8) represents a zircon aggregate hosted by plagioclase and quartz and consists of differently oriented irregularly shaped fragments. Some fragments seem detached from the aggregate and surrounded by host plagioclase in the 2-D section (Fig. 8c, upper right, lower left). Zircon fragments have roundish or angular shape and often form triple junctions, and are separated by low- and high-angle boundaries. Misorientation angles between fragments range from $2^{\circ}$ to more than $15^{\circ}$ (Fig. 8c). The orientation of the subgrains within a cluster changes progressively, as shown by false-color highlighting of the misorientation with respect to a single reference point from $0^{\circ}$ (blue; top, Fig. 8a) to $26^{\circ}$ (red; bottom, Fig. 8a). Grain boundaries characterized by a CL-bright signal truncate oscillatory zoning (Fig. 8b). The distribution of misorientation axes does not show systematics of fragments rotation (Fig. 8e), and misorientation axes clustering is rather weak, consistent with crystallographic orientations that do not have a clear rotation trend (Fig. 8f). The misorientation axes are clustered around the zircon [113], [111] and [311] directions.

Grain BH12-07A_03a (Fig. 9a) is situated at the phase boundary between polycrystalline chlorite and K-feldspar, whereas grains BH12-07A_04 and BH12-07B_31b occur within biotite aggregates (Fig. 9b, c) and are decoupled from the matrix. Decoupling is identified by normal and reversed drag of adjacent biotite and also by pressure shadow filled with titanite (Fig. 9b). All three presented grains have subidiomorphic shape, are elongated with aspect ratios $2: 3-1$ : 2 and display subgrains with $4-10^{\circ}$ orientation deviation from a reference point. Grains show systematic lattice rotation about zircon [001] (right column). According to the subgrain boundary configurations, the active slip system in these grains is $<100>\{010\}$. The [001] directions of all three grains have a similar orientation (highlighted by a red circle) coinciding with that of crystal BH12-07B_28 (Fig. 4f); they are parallel with the stretching lineation of the sample.

\section{Discussion}

\subsection{Static dissolution-reprecipitation vs. crystal-plastic deformation}

Hydrothermally altered zircon zones resembling those in grain BH12-01B_29 (Fig. 2) have been described from natural rocks (e.g., Corfu et al., 2003, and references therein) and produced experimentally (Geisler et al., 2001, 2003). Altered zones that crosscut the initial zoning are characterized by a sharp front with curved geometry. Recrystallized lattice domains are marked by increased CL intensity compared to the signal from the matrix, which is considered to be a result of dissolution-precipitation, which decreased lattice defect density (Corfu et al., 2003; Geisler et al., 2001, 2003). There are at least four arrangements of CL-bright domains observed in investigated zircons: (i) CL-bright domains extending into the inner parts of a grain, forming closed core zones (e.g., Fig. 2b, upper left part, lower right part); (ii) CL-bright domains along fractures or subgrain boundaries (Figs. 6b, 8b); 
(iii) occurring as rims, framing the central part of a crystal (Fig. 10b); or (iv) covering the entire grain (Fig. 12b).

(i) (i)Zircon grain BH12-01B_29 (Fig. 2, sample BH1201-I) does not show a genetic relation of CL-bright homogeneous domains and crystal-plastic deformation. Recrystallized domains do not exhibit any significant misorientation with respect to the rest of the grain (Fig. 2d). Slight misorientation corresponding to intensity variations in the CL pattern can be interpreted as being related to a compositional variation and the increased degree of crystallinity (Fig. 2a, b). Homogeneous CL-bright domains (i) forming closed zones with half-circular shape inside the crystal frequently occur in sample BH12-01-I. Their occurrence is independent of whether grains show crystal-plastic deformation microstructures or not, leading to the conclusion that crystal-plastic deformation and recrystallization in this sample have no evident mutual effect.

(ii) (ii)In contrast, grain BH12-01B_22 (sample BH12-01II) demonstrates a genetic relation between recrystallized zones and crystal-plastic deformation microstructures. The CL-bright feature at the left of inclusion is also visible in the SE image (Fig. 6c, white arrows) and spatially corresponds to the trace of the subgrain boundary that accumulates the largest misorientation angle (Fig. 6b, white arrows; d, boundary color-coded green). However, the significant width of this CL bright zone contrasts with similar features observed in grains BH12-05B_07, BH12-07B_15a and 28. The geometric relationship between CL-signal characteristics and subgrain boundaries indicates that hydrothermal recrystallization postdated crystal-plastic deformation and exploited deformation microstructures. Subtle fractures in the hosting plagioclase (Fig. 6c, black arrows) are spatially associated with the crystal-plastically deformed part of the zircon grain and might be related to the slight volume expansion of the zircon grain's tip due to recrystallization and/or, more likely, metamictization of the CL-dark core.

(iii) (iii)In grain IV12-06C_05 (Figs. 10 and 11), the CLbright recrystallized rim (iii) is locally deformed and exposed to the local grain size reduction. The degree of crystallinity is rather low where lattice distortion took place. The local distortion of the recrystallized rim shows that metamorphic recrystallization of zircon predates plastic deformation. The thickness of the recrystallized rim is reduced in the crystal-plastically deformed zone when comparing with the average thickness of the undistorted rim in the lower portion of the grain. The bright rim almost disappears where newly formed grains are observed (Fig. 10b, d-domains with green and blue contours). (iv) (iv)Grain IV12-06C_16 is homogeneously bright in the CL image (Fig. 12b), potentially reflecting complete recrystallization. Homogenization of the crystal lattice and chemical composition - if predating deformation could explain the lack of strain localization and subgrain formation in this zircon grain. Another possibility is that the bright CL signal is generated by dislocations, which represent evenly distributed luminescence centers in the crystal lattice. The bright CL-signal induced by intrinsic defects in the crystal lattice, including dislocations, has been described for calcite, quartz and some synthetic materials (e.g., Goetze et al., 2001; Akchurin et al., 2009).

To summarize, zircon recrystallization in the investigated samples was supposedly induced by fluid infiltration. Where observed, the temporal relationship between hydrothermal recrystallization and crystal-plastic deformation may vary: in one sample, hydrothermal alteration clearly precedes crystalplastic deformation (IV12-06C_05) in the other postdates (BH12-01B_22). Hydrothermal alteration causing dissolution-precipitation may have been operating repeatedly at different stages and in different temperature regimes during the metamorphic evolution of the rocks.

\subsection{Microstructural analysis of different lattice distortion patterns}

Based on several natural examples we have demonstrated the variety of finite deformation patterns of plastically deformed zircons. The investigated zircon grains - when deformed show either high but coherent lattice strain without dislocation accumulation in (sub)grain boundaries (distortion type I), recrystallization by a polygonization (distortion type III) or a combination of both (type II).

\subsubsection{Distortion type (I)}

Type (I) finite deformation patterns are characterized by gradual intragranular lattice orientation changes affecting the entire zircon grain without any remarkable step or subgrain formation. Similar features have been described by Reddy et al. (2007), and very likely correspond to type (I) lattice distortions of the classification by Piazolo et al. (2012). Moser et al. (2009) describe this type of lattice distortion as a result of an impact event. We suggest that this distortion pattern formed due to deformation of the host strong matrix (plagioclase). Host plagioclase is uniformly bent around zircon (Fig. 12a, inset) and, due to a high degree of coupling, zircon has been deformed together with the host.

Uniform bending of the zircon lattice reaching intragranular misorientations up to $25^{\circ}$ (Fig. 13a) requires the presence and even distribution of geometrically necessary dislocations (GND), which form if the lattice rotations exceed its elastic limit. However, dislocations obviously are not mobile and therefore do not accumulate within (sub)grainboundaries. 
The degree of crystallinity and CL intensity does not significantly change across the zircon grain, which is a result of the uniform distortion (Fig. 12b). Distributed strain, accommodated by dislocations that are not accumulated in lowangle boundaries, does not allow for inferring active slip systems, and misorientation axes are scattered, with weak clustering around zircon [001], which is a commonly referenced misorientation axis (Leroux et al., 1999; Reddy et al., 2007; Kaczmarek et al., 2011; Timms et al., 2012b). Scattering of misorientation axes is caused by subordinated deformation together with the polycrystalline host plagioclase.

\subsubsection{Distortion type (II)}

This deformation pattern is accompanied by fragmentation at the margins and characterized by strong lattice distortion in local rim domains. Lattice distortion type (II) preferably develops in zircon domains adjacent to a strong phase, as well as in grains hosted by polycrystalline fine-grained matrix. The load exerted by strong neighboring grain leads to high differential stress and eventually to strain in specific grain domains. The upper left part of the zircon grain IV12-06C_05 was pressed into adjacent garnet grain (Fig. 10), resulting in high lattice strain with relatively large angular misorientations (Fig. 10a). In the study of Piazolo et al. (2012), this deformation pattern formation is explained as mutual "indentation" of rheologically hard grains, where one of the grains has so-called "Vickers indentation" and causes locally enhanced differential stress in the neighboring grain (Ferguson et al., 1987; Lloyd, 2000; Whitney et al., 2007). The indenter interpretation is appropriate for the specific case described in Piazolo et al. (2012). However, as we have shown, very similar deformation pattern in zircon can also form when two strong grains with relatively straight faces (in 2-D sections) are pressed into each other. Sometimes this distortion pattern forms in large zircon clasts that are hosted by a finecrystalline matrix.

Finite deformation pattern type (II) includes not only subgrain formation but also the formation of high-angle grain boundaries and grain size reduction. Dynamic recrystallization by a subgrain rotation mechanism initially causes the formation of low-angle boundaries, whereas progressive strain accumulation induces the rotation of subgrains and an increasing dislocation density in the subgrain boundaries that develop to the high-angle boundaries. Newly forming grains are observed in the Fig. 10d, contoured by green and blue lines.

The asterism of crystallographic orientations (Fig. 10f) evidences about several simultaneously operating slip systems with different misorientation axes, and points to locally high differential stress. These are the main misorientation axes observed, but there could be several subordinate axes operating simultaneously (Fig. 11a).

\subsubsection{Distortion type (III)}

Type (III) is characterized by "polygonization" (White, 1973, 1976; Poirier and Nicolas, 1975; Gerald et al., 1983; Behrmann, 1985), due to formation of slightly misoriented subgrains, which lack internal lattice strain and are separated by subgrain boundaries. Subgrain boundaries form closed contours and often have a bright CL signature (e.g., Figs. 3-5). All subgrains are clearly visible in the orientation contrast images, and more pronounced than in the case of lattice distortion type (II) (Fig. 10e). The type (III) distortion pattern presumably results from mechanisms such as formation and migration of dislocations, thermally controlled recovery and recrystallization by rotation of subgrains. These are the components of dislocation creep regime, and they lead to accumulation of dislocations within subgrain boundaries (e.g., Hobbs, 1968; White, 1973, 1976; Poirier and Nicolas, 1975; Behrmann, 1985; Drury and Urai, 1990; Poirier, 1985).

The type (III) finite deformation pattern can be conditioned by variety of factors controlling the crystal-plastic behavior of zircon. The following discussion will present several cases of the commonly observed end members that are possible for this distortion type; however, most grains of this type fall between the following end members:

Case 1 is defined by favorable shape orientation of deformed grain in the local stress field. These zircon finite deformation patterns develop only locally; distortion, for example, affects the portion of grain comprising the intersection of prism and pyramid faces in euhedral prismatic zircon grains (or similar geometry, e.g., Figs. 3, 9b; Moser et al., 2011). The observed local deformation of the grain (Figs. 3c, 9b) implies the presence of differential stress and therefore inhomogeneous strain distribution within the grain. This scenario occurs when simple shear affects strong elliptical inclusion in a softer matrix or inclusion that is decoupled from its matrix (Kenkmann, 2000; Schmid and Podladchikov, 2005). The highest pressure affects those portions of matrix which are adjacent to the clast boundary segments normal to the shortening direction (e.g., Schmid and Podladchikov, 2004; Manktelow, 2008). According to numerical modeling (Schmid and Podladchikov, 2005), portions of the clast that are exposed to relatively higher pressure experience differential stress. However, most of the strain is accommodated within soft matrix and the resulting intragranular misorientation of zircons is subtle $\left(<5^{\circ}\right)$. Various slip systems are active. Portions of grain which are not affected by differential stress remain undistorted.

This finite deformation pattern can be observed in grain BH12-05B_07 (Fig. 3). Grains portion adjacent to pyramid-prism conjugation is deformed. Presumably, distortion in this domain formed due to differential stress, and therefore inhomogeneous strain distribution during shearing, and was defined by decoupling from the matrix. Another example is elliptical grain BH12-07A_04 (Fig. 9b), which is deformed 
at its opposite portions; the shortening direction could be reconstructed from the distribution of distorted domains.

Case 2 is defined by favorable crystallographic orientation in the local stress field. These lattice distortion patterns are controlled by the crystallographic anisotropy of zircon, causing slip along the dominant slip systems that are genetically connected with the main crystallographic axes: $<001>$ and $<100>$. In order to activate dominant slip systems, a certain crystallographic orientation with respect to the local stress field is preferable. Grains characterized by this deformation pattern usually perform specific shape geometry; they are rather short prismatic with the aspect ratio of $1: 2-1: 3$, or isometric, and some of them have a nearly rectangular shape (Figs. 4, 5). This case of lattice distortion is mostly observed in the grains hosted by soft matrix or decoupled from the matrix. We use the term "decoupling" to mean that the grain is able to slide along the grain-matrix interface. Decoupling from the matrix can be identified (i) by the presence of coating at the interface (recrystallized biotite, for example, grain BH12-07B_15a), by (ii) opening of voids at the interface (grains BH12-07A_04 (pressure shadow, filled with titanite), BH12-07B_15a, 28), and by (iii) evidence of sliding of inclusion in matrix when the elements of inclusion and matrix are shifting with respect to each other (e.g., Kenkman, 2000; grains BH12-07A_04, BH12-07B_28). Generally, most of the grains hosted by biotite are decoupled from it, because biotite is a soft phase and strong clasts can easily slip along the interface.

Assuming that the boundary wall is parallel to $\{100\}$ and contain misorientation axis in sample BH12-07B_28 (Fig. 4d, f), the resulting slip systems are $<100>\{010\}$. We assert these systems as "dominant", as they are more favorable for zircon crystals (e.g., Leroux et al., 1999; Kaczmarek et al., 2011; Reddy et al., 2007, 2009; Timms et al., 2012b; Piazolo et al., 2012), and the other systems, if active, as "unfavorable", as they are less energetically preferable. The microstructure of grain BH12-07B_15a (Fig. 5) implies the operation of at least two slip systems. Accommodating slip by edge dislocations yields either $<100>\{010\}$ or $<010>\{001\}$, respectively; a twist boundary forms in the case of misorientation axis parallel to [100] and subgrain boundary (100). The observation of radial subgrain boundaries may lead to the conclusion that they are fractures formed due to expansion of the metamicted core. In contrast, in this case the core shows a comparatively high degree of crystallinity (Fig. 5b, colored dots), although heterogeneities due to growth zoning certainly may influence the development of the deformation pattern.

The preferable slip along $\{100\}$ or $\{001\}$ is facilitated by the specific crystallographic orientation with respect to a local stress field. Orientation helps the resolved shear stress (CRSS) to be reached along the specific glide plane (Hobbs, 1985). Similarly, orientated zircon grains in one sample have similar lattice distortion patterns (e.g., BH12-07B_28, 31b; BH12-07A_03a, 04; Figs. 4, 9); they indicate activation of the slip systems $<100>\{010\}$. Grains BH12-07A_03a, BH12-07B_28 and 31b show two symmetrical "lobes" that are displaced along the subgrain boundary tracing from the lower left to the upper right corner of each grain (Figs. 4a, $9 \mathrm{a}-\mathrm{b})$.

Case 3 is characterized by subgrain formation with boundaries emanating from mineral inclusions in zircon (Fig. 6a).

This geometric arrangement of subgrain boundaries could be a result of pinning of dislocations by obstacles during recovery and recrystallization of the crystal lattice (Drury and Urai, 1990). However, a more favorable scenario describes xenocrystic cores, inclusions, pores and fractures within a crystal as structural heterogeneities that may induce inhomogeneous stress distribution (Mancktelow, 2008; Timms et al., 2012a) and strain localization during deformation. Stress may be heterogeneously distributed in the grain around mineral inclusion or pore, which leads to local lattice distortion even within the central portions of grains during post-growth deformation (Timms et al., 2012a).

Superimposing the traces of subgrain boundaries from grain BH12-01B_22 in the pole figure gives two general families of planes, where one contains the rotation axis and the other is rather normal to it (Fig. 6f). From this observation we infer that the two families of subgrain boundaries represent tilt and twist walls, respectively. Thus, the glide system for the edge dislocations presumably is $<-103>\{30-1\}$. The activation of slip along the high Miller indices plane may be controlled by the inclusion geometry. Grain boundary sliding at the inclusion-host interface may have induced the activation of specific slip planes within the enclosing host (e.g., Raj and Ashby, 1971; Wang et al., 2014). Another grain that shows subgrain boundaries emanating from a mineral inclusion is BH12-07A_04 (Fig. 9b). The subgrain adjacent to the inclusion (Fig. 9b, marked by arrow) forms due to the presence of differential stress around the inclusion during shearing.

Case 4 shows a deformation pattern controlled by the microstructure of the host phase, i.e., phase-, grain- or subgrain boundary structure of the host. As the applied differential stress is transferred to the zircon by the host phase, there seems to be a relationship between the zircon subgrain boundary geometry and host (sub)grain boundary geometry, especially in the case of a strong host/coupling with host. (Sub)grain boundaries of the host grain(s) can be often traced inside the hosted zircon grain as subgrain boundaries or fractures as, for example, in grain BH12-04_11 (Fig. 7a, d, arrows). Subgrain boundaries in elongated zircon BH12-04_11 relate to crystal-plastic deformation by subgrain rotation, because misorientation axes density distribution demonstrates a well-defined cluster (Fig. 7e). Coupling of zircon with a strong host mineral prevents the activation of energetically preferable slip systems in zircon and therefore causes the formation of high indexed misorientation axes.

Case 5 is characterized by zircons, where (sub)grain boundaries formed due to fragmentation, fragments rotation 
with respect to each other, and subsequent fracture healing, as in the sample BH12-02_45. This case of finite deformation patterns predominates in amphibolite-facies rocks which were affected by intensive fluid circulation that induced fracture healing by material precipitation. Formation of the new grains occurs due to progressive subgrain rotation recrystallization, or as a result of cataclastic behavior due to high strain rates at comparatively low temperatures. A similar process occurring in zircon grains was described and discussed in detail by Rimsa et al. (2007). In this case, traces of former fractures and/or (sub)grain boundaries are clearly shown as bright CL domains and are often decorated by inclusions or pores (Fig. 8b, d). This deformation pattern reflects the mylonitization process taking place within the high-temperature shear zones. Fine-grained zircon found in ultramylonite, characterized by a dark CL core and a thin bright outer rim (Fig. 6b), possibly represents fragments of large grains detached from a parent grain this way.

\subsection{CL imaging and Raman spectroscopy}

Subgrain boundaries resulting from deformation type (III) often demonstrate a brighter CL signal than the dislocationfree domains (Figs. 3b, 4b, 5b, 8b). A bright CL response linked to deformation features has been already described in the literature (Piazolo et al., 2012; Timms and Reddy, 2009). It has been shown repeatedly that ductile deformationrelated microstructures in zircon associated with compositional changes often influence the CL signal (Reddy et al., 2006, 2007; Timms et al., 2006). Therefore, a bright CL signal is attributed not only to a high dislocation density but also to a potential trace element enrichment/depletion along the subgrain boundaries, which is supposedly capable of disturbing the isotopic system of the bulk grain (Moser et al., 2009; Timms et al., 2006, 2011).

The results of Raman spectroscopy do not indicate any ductile deformation-related metamictization of zircon grains that belongs to type (III) deformation patterns. This is an indicator of a high level of recovery in these grains. In contrast, zircons from granulite facies rocks contain homogeneously distributed dislocations within specific grain domains (IV1206C_05, type II) or within the entire grain (IV12-06C_16, type I), leading to a decreased degree of crystallinity.

\subsection{What deformation conditions and host environment facilitate crystal-plastic deformation in zircon?}

The deformation regime of minerals depends on the minerals' properties at the given environmental conditions. The following conditions facilitate zircon crystal-plastic deformation.

Temperature. Finite deformation patterns in zircon result from various combinations of temperature-dependent deformation mechanisms (diffusion of vacancies, solution-precipitation, dislocation formation and motion by glide and climb, grain boundary sliding, etc.) (e.g., Ion et al., 1982; Poirier, 1985). In our study, zircon deformed under higher temperatures (granulite facies) mostly shows finite lattice distortion pattern type (I) and (II), and zircon deformed under lower temperatures (amphibolite facies) mostly shows distortion type (III) (Fig. 14a-c). However, the difference in distortion patterns can be influenced not by temperature of deformation but by duration of recovery. Recovery was presumably longer for amphibolite-facies rocks, probably due to overprinted greenschist-facies metamorphism, resulting in the formation of dislocation-free subgrains in zircon (e.g., Hobbs, 1968; White, 1973, 1976; Gerald et al., 1983).

Differential stress. Distribution, magnitude and direction of applied stress can influence the deformation behavior. GNDs form under lithostatic pressure and applied differential stress; therefore, the dislocation density in the deformed crystal is stress-dependent (Ranalli, 1995). The orientation of differential stress with respect to the lattice orientation influences the crystal-plastic behavior (Reddy and Buchan, 2005; Kaczmarek et al., 2011). If loading is applied parallel to a certain crystallographic plane and deformation conditions are achieved at that plane, in-plane slip systems can be activated (Dahlberg et al., 2014). As we have demonstrated, specific crystallographic orientation relative to the local stress field causes glide along Miller low-index planes (Figs. 4, 9), which activates energetically preferable slip systems.

As shown by Kenkmann (2000) and Schmid and Podladchikov (2005), simple shear causes an inhomogeneous spatial distribution of pressure and differential stress within a strong clast that is decoupled from soft matrix. This, in turn, causes an inhomogeneous distribution of strain inside the clast. We have demonstrated that these agents in some cases lead to the localized lattice distortion of specific zircon domains (finite deformation types II and III, cases 1 and 2). In type (II) this is caused by grain pressed against a stronger phase. Specific grain shape orientation in a local stress field induces applied differential stress in specific grain domains (type III, case 1); specific crystallographic orientation in a stress field induces applied differential stress on certain crystallographic planes (type III, case 2).

We suggest that grain BH12-07A_04 (Fig. 9b) represents a natural example of the 2-D models of heterogeneous stress distribution within an elliptical inclusion (Schmid and Podladchikov, 2005). The portions of grain BH12-07A_04 that are distorted correspond spatially to the portions of modeled clast affected by high pressure (differential stress). The growth of the titanite next to zircon boundary (Fig. 9b, Ttn) spatially corresponds to pressure shadow in the models.

Grain shape. Specific grain shape can affect the lattice distortion patterns of zircon. For example, it has been demonstrated by Reddy et al. (2009) that grains with euhedral shape that were deformed in syn-magmatic conditions soon after crystallization are distorted in a uniform way: they are mostly deformed on their flanks with rotation axis [001] and presumable slip system $<100>\{010\}$. As we have demonstrated, 
grains from the sample BH12-07 (Figs. 4, 9) have a euhedral short-prismatic shape and their $c$ axes are parallel to the stretching lineation. Such orientation likely induced specific crystal-plastic deformation mechanisms with activation of the slip system $<100>\{010\}$. In sample IV12-06C, zircon grains with isometric roundish shape appear to be undeformed, whereas crystal plastic deformation features are restricted to irregularly shaped grains (Figs. 10,12). This is consistent with abovementioned inhomogeneous stress and strain distributions during deformation caused by specific grain shape.

Host matrix. According to the Fig. 14a-c, more deformed rocks (i. e. stronger foliated, stronger folded) contain higher ratio of deformed zircon grains than non-foliated rocks from the same sequence.

Based on the new data, we can demonstrate that the degree of coupling with the host matrix is an important agent controlling zircon distortion, as well as the zircon/host difference in hardness. The strength of coupling between clast and matrix influences the magnitude of differential stress within the clast (Kenkmann, 2000) and thus affects the finite deformation pattern. Difference in hardness between host and inclusion define the external stress magnitude that the host phase transfers to the inclusion. Crystal-plastic deformation of zircon decoupled from host mica results in locally high differential stress and activation of dominant slip systems (type III, case 2). In contrast, when a single grain is deformed while being enclosed by a strong phase and/or strongly coupled with the matrix, there is no differential stress within the grain (e.g., Mancktelow, 2008). Therefore, active glide planes in zircon are controlled by the host phase; and unfavorable slip planes are activated. Thus, zircon often forms subgrain boundaries that correlate with host mineral deformation features (type III, case 4). When the strong host shows gradual lattice rotation, enclosed zircon also rotates gradually with scattering of misorientation axes (type I, Fig. 12a). According to Kenkmann (2000), clasts that are well coupled with the matrix can show a high amount of defects, concentrated at the rim as in grain IV12-06C_05 (pattern type II).

The distribution of misorientation axes statistically depends on host mineral. Based on 60 deformed grains investigated for the current study, the density distribution of the misorientation axes have been plotted, resulting in six distinct areas in the pole figure (Fig. 14d). In the most common case, misorientation axes are spread along the $<001>$ direction; a large cluster of misorientation axes is located around $<320>$ and orientation clusters around $<100>$ and $<111>$. Less commonly, the misorientation axes are clustered around $<201>$ and $<203>$. Thus, misorientation axes do not necessarily coincide with the most common rotation axes $<001>$ and $<100>$ (Reddy et al., 2007; Kaczmarek et al., 2011), but can be activated in different crystal directions controlled by a number of agents that influence the mechanical behavior of the system. Grains hosted by biotite or a fine-grained matrix mostly belong to ar- eas around $<001>$ and $<100>$, whereas grains hosted by feldspars preferably occupy areas around $<110>,<210>$ and $<311\rangle$. This regularity demonstrates that the ratio between clast and matrix hardness may control slip inside the clast. The higher this ratio is, the less the degree of mechanical coupling, and thus the higher the probability of activation of the dominant or energetically preferable slip systems in the clast.

Internal mechanical weakness. If the grain contains some mechanical weakness (e.g., inclusion, crack, pore, core-mantle structure), during deformation, differential stress occurs in the domain that contains mechanical weakness (Timms et al., 2012a). The sources of internal inhomogeneous stress could be, for example, fractures, growth zoning, inclusions or pores (Macktelow, 2008). Finite deformation patterns of type (III), case 3, can be described as lattice distortion that follows the internal mechanical weakness in zircon crystal structure, where the sources of internal anisotropy are mineral inclusions.

\subsection{What factors could influence zircon finite distortion patterns?}

Based on empirical observations, the grains with structure types I-III accommodate approximately the same amount of strain. Internal misorientation increases from patterns type (III) $\left(3-10^{\circ}\right)$ to type (I) $\left(7-25^{\circ}\right)$, and the highest internal misorientation accompanied by marginal fragmentation is observed for type (II) $\left(15-40^{\circ}\right)$. We assume that differential stress increases accordingly.

At moderate differential stress and strain rate, GDNs are expected to form, glide and climb. Well-defined subgrain walls are formed by dislocation glide, and subgrains are recovered by dislocation climb (e.g., Hobbs, 1986; White, 1973, 1976; Drury and Urai, 1990). At low differential stress, the rate of dislocation formation is lower, or at least the same as the rate of dislocation recovery. As a result, we observe subgrain rotation recrystallization, or polygonization, which is illustrated by deformation patterns of type (III) (e.g., Hobbs, 1968; Gleason and Tullis, 1995).

At higher stress and strain rate, GDNs are produced within the grain with higher rates; if there is no recovery, GND density increases, and they tangle, resulting in no ability to move (e.g., McLaren and Retchford, 1969; Leroux et al., 1999). Thus there is no evidence of dislocation motion, and therefore no formation of subgrain boundaries. The grain gradually bends, resulting in the deformation patterns type (I).

If the stress and strain rate increase, the increasing density of GNDs may eventually result in strain hardening and brittle deformation (Poirier, 1985). Thus, brittle deformation and marginal fragmentation of the grain, coupled with gradual bending of the lattice is observed, as in distortion patterns type (II). If the high stress continues to operate, we expect complete fragmentation of a grain into a fine-grain aggregate. 
In more detail, the ratio between the rate of dislocations' formation and the rate of dislocations' motion, which are stress dependent, should be responsible for the variety of lattice distortion patterns observed. A model of zircon crystalplastic deformation is based on comparison of zircon with various distortion patterns. The schematic diagram proposed for different finite deformation patterns, depending on stress (GND formation/GND motion rates) and strain rate, is presented in Fig. 15.

\section{Conclusions}

The detailed investigation of the deformation behavior of fine-grained zircon in association with the host phases provides important new information on the zircon crystal-plastic deformation in common metamorphic settings:

1. New microstructural and textural data describe three clearly distinguished crystal-plastic distortion patterns of zircon. Type (I) distortion patterns are characterized by comparatively large intragranular orientation variations; subgrains and subgrain boundaries are absent. Type (II) distortion patterns are indicated by gradual bending of the crystal lattice coupled with (sub)grain boundary formation exhibiting concentric shape and significant intragranular misorientation. Distortion patterns of type (III) show the formation of welldefined low-angle boundary networks separating strainfree subgrains.

2. During deformation at amphibolite-granulite facies metamorphic conditions, fine-grained zircon behaves identically to coarse-grained zircon (compared with, for example, Reddy et al., 2007; Piazolo et al., 2012).

3. Zircon crystal-plastic deformation is facilitated by the following agents: specific orientation of the local stress field with respect to the zircon lattice orientation and grain shape, soft host phase(s), decoupling with the matrix and internal mechanical anisotropy.

4. Host phase(s) play the leading roles in misorientation axes distribution. In favorable cases (e.g., when the matrix is soft), the following energetically preferable slip systems in zircon are active: $<100>\{010\}$, $<010>\{001\}$ and $<001>\{010\}$. When the matrix is strong, and/or when the grain is strongly coupled with its host, unfavorable slip along the high indexed crystallographic planes and unfavorable slip systems can be activated.

5. Difference in zircon finite deformation patterns I-III is considered to be dependent on the strain rate and the ratio between dislocations' formation and dislocations' motion rates, which are, in turn, stress dependent.
6. Hydrothermal alteration of zircon does not obviously induce or influence crystal-plastic deformation, although in some cases a temporal and spatial relationship between those two processes can be inferred.

Acknowledgements. This study was funded by the University of Vienna (doctoral school "DOGMA", project IK 052) and the Austrian Science Foundation Fund (FWF): I471-N19, which is part of the DFG-FWF-funded international research group FOR741-DACH.

The authors are grateful to Rainer Abart, Christian Auer, Claudia Beybel, Franz Biedermann, Bernhard Grasemann, Sigrid Hrabe, Matthew Huber, Hugh Rice, Claudia Trepmann, and all colleagues of the FOR741 research group for fruitful discussions, as well as the Geologische Bundesanstalt (GBA) of Austria for access to the SEM.

Edited by: L. Menegon

\section{References}

Akchurin, M. Sh., Zakalyukin, R. M., Kaminsky, A. A., and $\mathrm{Ku}-$ penko, I. I.: Role of Twinning in Plastic Deformation, Crystallogr. Rep., 55, 621-625, 2010.

Bachmann, F., Hielscher, R., and Schaeben, H.: Texture Analysis with MTEX - Free and Open Source Software Toolbox, Sol. St. Phen., 160, 63-68, 2010.

Bachmann, F., Hielscher, R., and Schaeben, H.: Grain detection from $2 \mathrm{~d}$ and $3 \mathrm{~d}$ EBSD data-specification of the MTEX algorithm, Ultramicroscopy, 111, 1720-1733, 2011.

Barboza, S. A., Bergantz, G. W., and Brown, M.: Regional granulite facies metamorphism in the Ivrea zone: is the Mafic Complex the smoking gun or a red herring?, Geology, 27, 447-450, 1999.

Behrmann, J. H.: Crystal plasticity and superplasticity in quartz: a natural example, Tectonophysics, 115, 101-129, 1985.

Brodie, K. H., Rutter, E. H., and Evans, P.: On the structure of the Ivrea-Verbano Zone (northern Italy) and its implications for present-day lower continental crust geometry, Terra Nova, 4, 34-39, 1992.

Cherniak, D. J. and Watson E. B.: Diffusion in Zircon, in: Ziron, edited by: Hanchar, J. M. and Hoskin, P. W. O., Mineralogical Society of America and Geochemical Society, Reviews in Mineralogy and Geochemistry, Washington DC, 53, 113-143, 2003.

Cherniak, D. J., Lanford, W. A., and Ryerson, F. J.: Lead diffusion in apatite and zircon using ion implantation and Rutherford Backscattering techniques, Geochim. Cosmochim. Ac., 55, 1663-1673, 1991.

Corfu, F., Hanchar, J. M., Hoskin P. W. O., and Kinny, P.: Atlas of zircon textures, in: Zircon, edited by: Hanchar, J. M. and Hoskin, P. W. O., Mineralogical Society of America and Geochemical Society, Reviews in Mineralogy and Geochemistry, Washington DC, 53, 468-500, 2003.

Dahlberg, C. F. O., Saito, Y., Öztop, M. S., and Kysar, J. W.: Geometrically necessary dislocation density measurements associated with different angles of indentations, Int. J. Plasticity, 54, 81-95, 2014.

Davis, D. W., Williams, I. S., and Krogh, T. E.: Historical development of zircon geochronology, in: Zircon, edited by: Hanchar, J. 
M. and Hoskin, P. W. O., Mineralogical Society of America and Geochemical Society, Reviews in Mineralogy and Geochemistry, Washington DC, 53, 145-181, 2003.

Drury, M.R. and Urai, J. L.: Deformation-related recrystallization processes, Tectonophysics, 172, 235-253, 1990.

Erdmann, S., Wodicka, N., Jackson, S. E., and Corrigan, D.: Zircon textures and composition: refractory recorders of magmatic volatile evolution?, Contrib. Mineral. Petr., 165, 45-71, 2013.

Erickson, T. M., Cavosie, A. J., Moser, D. E., Barker, I. R., and Radovan, H. A.: Correlating planar microstructures in shocked zircon from the Vredefort Dome at multiple scales: Crystallographic modeling, external and internal imaging, and EBSD structural analysis, Am. Mineral., 98, 53-65, 2013a.

Erickson, T. M., Cavosie, A. J., Moser, D. E., Barker, I. R., and Radovan, H. A., and Wooden, J.: Identification and provenance determination of distally transported, Vredefort-derived shocked minerals in the Vaal River, South Africa using SEM and SHRIMP-RG techniques, Geochim. Cosmochim. Ac., 107, 170-188, 2013b.

Ferguson, C. C., Lloyd, G. E., and Knipe, R. J.: Fracture mechanics and deformation processes in natural quartz: a combined Vickers indentation, SEM and TEM study, Can. J. Earth Sci., 24, 544-555, 1987.

Flowers, R. M., Schmitt, A. K., and Grove, M.: Decoupling of U-Pb dates from chemical and crystallographic domains in granulite facies zircon, Chem. Geol., 270, 20-30, 2010.

Geisler, T., Ulonska, M., Schleicher, H., Pidgeon, R. T., van Bronswijk, W.: Leaching and differential recrystallization of metamict zircon under experimental hydrothermal conditions, Contrib. Mineral. Petr., 141, 53-65, 2001.

Geisler, T., Kurtz, R., Pidgeon, R. T., van Bronswijk, W.: Transport of uranium, thorium and lead in metamict zircon under low-temperature hydrothermal conditions, Chem. Geol., 191, 141-154, 2002.

Geisler, T., Pidgeon, R. T., Kurtz, R., Bronswijk, W., and Schleicher, H.: Experimental hydrothermal alteration of partially metamict zircon, Am. Mineral., 88, 1496-1513, 2003.

Gerald, F. J. D., Etheridge, M. A., and Vernon, R. H.: Dynamic recrystallization in a naturally deformed albite, Texture Microstruct., 5, 219-237, 1983.

Gleason, G. C. and Tullis, J.: A flow law for dislocation creep of quartz aggregates determined with the molten salt cell, Tectonophysics, 247, 1-23, 1995.

Goetze, J., Ploetze, M., and Habermann, D.: Origin, spectral characteristics and practical applications of the cathodoluminescence (CL) of quartz - a review, Miner. Petrol., 71, 225-250, 2001.

Grange, M. L., Pidgeon, R. T., Nemchin, A. A., Timms, N. E., and Meyer, $\mathrm{C}$. : Interpreting $\mathrm{U}-\mathrm{Pb}$ data from primary and secondary features in lunar zircon, Geochim. Cosmochim. Ac., 101, 112-132, 2013.

Hobbs, B. E.: Recrystallization of single crystals of quartz, Tectonophysics, 6, 353-401, 1968.

Hobbs, B. E.: The geological significance of microfabric analysis, in: Preferred orientation in deformed metal and rocks. An introduction to modern texture analysis, edited by: Wenk, H. R., Elsevier Inc., 463-484, 1985.

Hofmann, A. E., Valley, J. W., Watson, E. B., Cavosie, A. J., and Eiler J. M.: Sub-micron scale distribution of trace elements in zircon, Contrib. Mineral. Petr., 158, 317-335, 2009.
Ion, S. E., Humphreys, F.-J., and White, S.-H.: Dynamic recrystallization and the development of microstructure during the high temperature deformation of magnesium, Acta Metall., 30, 1909-1919, 1982.

Jenkins, C. H. M. and Mellor, G. A.: Investigation of the behaviours of metals under deformation at high temperature. I - structural changes in mild steel and commercial iron during creep, J. Iron Steel Inst., 132, 179-227, 1935.

Kaczmarek, M. A., Reddy, S. M., and Timms, N. E.: Evolution of zircon deformation mechanisms in a shear zone (Lanzo massif, Western-Alps), Lithos, 127, 414-426, 2011.

Kenkmann, T.: Processes controlling the shrinkage of porphyroclasts in gabbroic shear zones, J. Struct. Geol., 22, 471-487, 2000.

Klötzli, U. S., Sinigoi, S., Quick, J. E., Demarchi, G., Tassinari, C. C. G., Sato, K., and Günes, Z.: Duration of igneous activity in the Sesia Magmatic System and implications for hightemperature metamorphism in the Ivrea-Verbano deep crust, Lithos, 206-207, 19-33, 2014.

Lloyd, G. E.: Grain boundary contact effects during faulting of quartzite: an SEM/EBSD analysis, J. Struct. Geol., 22, 1675-1693, 2000.

MacDonald, J. M., Wheeler, J., Harley, S. L., Mariani, E., Goodenough, K. M., Crowley, Q., and Tatham, D.: Lattice distortion in a zircon population and its effects on trace element mobility and $\mathrm{U}-\mathrm{Th}-\mathrm{Pb}$ isotope systematics: examples from the Lewisian Gneiss Complex, northwest Scotland, Contrib. Mineral. Petr., 166, 21-41, 2013.

Mainprice, D., Hielscher, R., and Schaeben, H.: Calculating anisotropic physical properties from texture data using the MTEX open source package, in: Deformation Mechanisms, Rheology and Tectonics: Microstructures, Mechanics and Anisotropy, edited by: Perior, D. J., Rutter, E. H., and Tatham, D. J., Geological Society, London, Special Publications, 360, 175-192, 2011.

Mancktelow, N. S.: Tectonic pressure: theoretical concepts and modelled examples, Lithos, 103, 149-177, 2008.

Mancktelow, N. S.: Behaviour of an isolated rimmed elliptical inclusion in 2-D slow incompressible viscous flow, J. Struct. Geol. 46, 235-254, 2013.

McLaren, A. C. and Retchford, J. A.: Transmission electron microscope study of the dislocations in plastically deformed synthetic quartz, Phys. Status Solidi, 33, 657-668, 1969.

McLean, D.: Crystal fragmentation in aluminium during creep, J. Inst. Metals, 81, 287-292, 1952.

Miller, C., Konzett, J., Tiepolo, M., Armstrong, R. A., and Thöni, M.: Jadeite-gneiss from the eclogite zone, Tauern Window, Eastern Alps, Austria: metamorphic, geochemical and zircon record of a sedimentary protholith, Lithos, 93, 68-88, 2007.

Moser, D. E., Davis, W. J., Reddy, S. M., Flemming, R. L., and Hart, R. J.: Zircon U-Pb strain chronometry reveals deep impacttriggered flow, Earth Planet. Sci. Lett., 277, 73-79, 2009.

Moser, D. E., Cupelli, C. L., Barker, I. R., Flowers, R. M., Bowman, J. R., Wooden, J., and Hart, J. R.: New zircon shock phenomena and their use for dating and reconstruction of large impact structures revealed by electron nanobeam (EBSD, CL, EDS) and isotopic $\mathrm{U}-\mathrm{Pb}$ and (U-Th)/He analysis of the Vredefort dome, Can. J. Earth Sci., 48, 117-139, 2011. 
Nemchin, A., Timms, N. E., Pidgeon, R., Geisler, T., Reddy, S. M., and Meyer, C.: Timing of crystallization of the lunar magma ocean constrained by the oldest zircon, Nat. Geosci., 2, 133-136, 2009.

Nye, J. F.: Some geometrical relations in dislocated crystals, Acta Metall., 1, 153-162, 1953.

Pennacchioni, G. and Mancktelow, N. S.: Nucleation and initial growth of a shear zone network within compositionally and structurally heterogeneous granitoids under amphibolite facies conditions, J. Struct. Geol., 29, 1757-1780, 2007.

Piazolo, S., Austrheim, H., and Whitehouse, M.: Brittle-ductile microfabrics in naturally deformed zircon: Deformation mechanisms and consequences for U-Pb dating, Am. Mineral., 97, 1544-1563, 2012.

Poirier, J. P.: Creep of Crystals: High-Temperature Deformation Processes in Metals, Ceramics and Minerals, in: Cambridge Earth science series, edited by: Cook, A. H., Harland, W. B., Hughes, N. F., Putnis, A., Sclater, J. G., and Thomson, M. R. A., Cambridge University Press, Leipzig, 260 pp., 1985.

Poirier, J. P. and Nicolas, A.: Deformation-induced recrystallization by progressive misorientation of subgrain-boundaries, with special reference to mantle peridotites, J. Geology, 83, 707-720, 1975.

Prior, D. J.: Problems in determining the orientation of crystal misorientation axes for small angular misorientations, using electron backscatter diffraction in the SEM, J. Microsc., 195, 217-225, 1999.

Quick, J. E., Sinigoi, S., Peressini, G., Demarchi, G., Wooden, J. L., and Sbisà, A.: Magmatic plumbing of a large Permian caldera exposed to a depth of $25 \mathrm{~km}$, Geology, 37, 603-606, 2009.

Raj, R. and Ashby, M. F.: On grain boundary sliding and diffusional creep, Metall. Trans., 2, 1113-1127, 1971.

Ranalli, G.: Rheology of the Earth, second edition, Chapman and Hall, London, 413 pp., 1995.

Reddy, S. M. and Buchan, C.: Constraining kinematic rotation axes in high-strain zones: a potential microstructural method?, in: Deformation mechanisms, rheology and tectonics: from mineral to the lithosphere, edited by: Gapais, D., Brun, J. P., and Cobbold, P. R., 243, Special publications, Geological society, London, 1-10, 2005.

Reddy, S. M. and Timms, N. E.: Deformation of zircon and implications for geochemistry and geochronology, Source Abstracts with Programs, Geol. Soc. Am., 42, p. 634 , 2010.

Reddy, S. M., Timms, N. E., Trimby, P., Kinny, P. D., Buchan C., and Blake, K.: Crystal-plastic deformation of zircon: a defect in the assumption of chemical robustness, Geology, 34, 257-260, 2006.

Reddy, S. M., Timms, N. E., Pantleon, W., and Trimby, P.: Quantitative characterization of plastic deformation of zircon and geological implications, Contrib. Mineral. Petr., 153, 625-645, 2007.

Reddy, S. M., Timms, N. E., Hamilton, P. J., and Smyth, H. R.: Deformation-related microstructures in magmatic zircon and implications for diffusion, Contrib. Mineral. Petr., 157, 231-244, 2009.

Redler, C., Johnson, T. E., White R. W., and Kunz, B. E.: Phase equilibrium constraints on a deep crustal metamorphic field gradient: metapelitic rocks from the Ivrea Zone (NW Italy), J. Metamorph. Geol., 30, 235-254, 2012.
Rimsa, A., Whitehouse, M. J., Johansson, L., and Pand iazolo, S.: Brittle fracturing and fracture healing of zircon: An integrated cathodoluminescence, EBSD, U-Th-Pb, and REE study. Am. Mineral., 92, 1213-1224, 2007.

Roters, F., Eisenlohr, P., Hantcherli, L., Tjahjanto, D. D., Bieler, T. R., and Raabe, D.: Overview of constitutive laws, kinematics, homogenization and multiscale methods in crystal plasticity finite-element modeling: Theory, experiments, applications, Acta Mater., 58, 1152-1211, 2010.

Rutter, E. H., Brodie, K. H., James, T., and Burlini, L.: Large-scale folding in the upper part of the Ivrea-Verbano zone, NW Italy, J. Struct. Geol., 29, 1-17, 2007.

Schmid, D. W. and Podladchikov, Y. Yu.: Are isolated stable rigid clasts in shear zones equivalent to voids?, Tectonophysics, 384, 233-242, 2004.

Schmid, D. W. and Podladchikov, Y. Yu.: Mantled porphyroclast gauges, J. Struct. Geol., 27, 571-585, 2005.

Schwartz, J. J., John, B. E., Cheadle, M. J., Wooden, J. L., Mazdab, F., Swapp, S., Craig, B., and Grimes, C. B.: Dissolution-reprecipitation of igneous zircon in mid-ocean ridge gabbro, Atlantis Bank, Southwest Indian Ridge, Chem. Geol., 274, 68-81, 2010.

Sellars, C. M.: Recrystallization of metals during hot deformation, Phil. Trans. R. Sot. Lond., 135, 513-516, 1978.

Selverstone, J.: Petrologic constraints on imbrication, metamorphism, and uplift in the SW Tauern Window, Eastern Alps, Tectonics, 4, 687-704, 1985.

Selverstone, J., Morteani, G., and Staude, J.-M.: Fluid channelling during ductile shearing: transformation of granodiorite into aluminous schist in the Tauern Window, Eastern Alps, J. Metamorp. Geol., 9, 419-431, 1991.

Silver, L. T. and Deutsch, S.: Uranium-lead isotopic variations in zircons: A case study, J. Geol., 71, 721-758, 1963.

Sinigoi, S., Quick, J. E., Demarchi, G., and Klötzli, U.: The role of crustal fertility in the generation of large silicic magmatic systems triggered by intrusion of mantle magma in the deep crust, Contrib. Mineral. Petr., 162, 691-707, 2011.

Sturm, R. and Steyrer, H. P.: Use of accessory zircon for the quantification of volume changes in ductile shear zones cutting plutonic rocks, Chem. Erde-Geothem., 63, 31-54, 2003.

Timms, N. E. and Reddy, S. M.: Response of cathodoluminescence to crystal-plastic deformation in zircon, Chem. Geol., 261, 11-23, 2009.

Timms, N. E., Kinny, P., and Reddy, S. M.: Enhanced diffusion of uranium and thorium linked to crystal plasticity in zircon, Geochem. T., 7, 10, doi:10.1186/1467-4866-7-10, 2006.

Timms, N. E., Kinny, P., Reddy, S. M., Evans K., Clark, C., and Healy, D.: Relationship among titanium, rare earth elements, $\mathrm{U}-\mathrm{Pb}$ ages and deformation microstructures in zircon: Implications for Ti-in-zircon thermometry, Chem. Geol., 280, 33-46, 2011.

Timms, N. E., Reddy, S. M., Gerald, F. J. D., Green, L., and Muhling, J. R.: Inclusion-localised crystal-plasticity, dynamic porosity, and fast-diffusion pathway generation in zircon, J. Struct. Geol., 35, 78-89, 2012a.

Timms, N. E., Reddy, S. M., Healy, D., Nemchin, A. A., Grange, M. L., Pidgeon, R. T., and Hart, R.: Resolution of impact-related microstructures in lunar zircon: a shock-deformation mechanism map, Meteorit. Planet. Sci., 47, 120-141, 2012 b. 
Trimby, P. W. and Prior, D. J.: Microstructural imaging techniques: a comparison of optical and scanning electron microscopy in the study of deformed rocks, Tectonophysics, 303, 71-81, 1999.

Urai, J. L., Means, W. D., and Lister, G. S.: Dynamic recrystallization of minerals, in: Mineral and Rock Deformation (Laboratory Studies), edited by: Heard, H. C., Geophysical Monograph of the American Geophysical Union, Washington DC, 36, 161-200, 1986.

Veselá, P., Söllner, F., Finger, F., and Gerdes, A.: Magmatosedimentary Carboniferous to Jurassic evolution of the western Tauern window, Eastern Alps (constraints from U-Pb zircon dating and geochemistry), Int. J. Earth Sci., 100, 993-1027, 2011.

Wang, L., Zhou, J., Zhang, S., Liu, Y., and Dong, S.: Effects of accommodated grain boundary sliding on triple junction nanovoid nucleation in nanocrystalline materials, Mech. Mater., 71, 10-20, 2014.
Watson, E. B., Wark, D. A., and Thomas, J. B.: Crystallization thermometers for zircon and rutile, Contrib. Mineral. Petr., 151, 413-433, 2006.

Wheeler, J., Mariani, E., Piazolo, S., Prior, D. J., Trimby, P. J., and Drury, M. R.: The weighted Burgers vector: a new quantity for constraining dislocation densities and types using electron backscatter diffraction on 2-D sections through crystalline materials, J. Microsc.-Oxford, 233, 482-494, 2008.

White, S.: Syntectonic recrystallization and texture development in quartz, Nature, 244, 276-278, 1973.

White, S.: The effects of strain and microstructure fabrics and deformation mechanisms in quartzite, Phil. Trans. R. Soc. London, 283, 69-86, 1976.

Whitney, D. L., Broz, M., and Cook, R. F.: Hardness, toughness, and modulus of some common metamorphic minerals, Am. Mineral., 92, 281-288, 2007. 